\title{
Backcasting in futures studies: a synthesized scholarly and planning approach to strategic smart sustainable city development
}

\author{
Simon Elias Bibri
}

\begin{abstract}
Backcasting as a scholarly and planning approach is increasingly used in futures studies in fields related to urban sustainability as an alternative to traditional planning approaches and a formal element of future strategic initiatives. It is viewed as a natural step in operationalizing sustainable development within different societal spheres. As a holistic urban development strategy, smart sustainable cities represent a manifestation of sustainable development as a process of change and a strategic approach to achieving the long-term goals of sustainability. Achieving smart sustainable cities represents an instance of urban sustainability, a concept that refers to a desired state in which a city strives to retain the balance of socio-ecological system through sustainable development as a desired trajectory. This long-term goal requires fostering linkages between scientific and social research, technological innovations, institutional practices, and policy design and planning in relevance to urban sustainability. It also requires a long-term vision, a transdisciplinary approach, and a system-oriented perspective on addressing environmental, economic, and social issues. These requirements are at the core of backcasting as an approach to futures studies. Backcasting is a special kind of scenario methodology to develop future models for smart sustainable city as a planning tool for urban sustainability. Goal-oriented backcasting approaches declare long-range targets that lie quite far in the future. Visionary images of a long-term future can stimulate an accelerated movement towards achieving the goals of urban sustainability. The backcasting approach is found to be well-suited for long-term urban sustainability solutions due to its normative, goal-oriented, and problem-solving character. Also, it is particularly useful when dealing with complex problems and transitions, the current trends are part of the problem, and different directions of development can be allowed given the wide scope and long time horizon considered. A number of recent futures studies using backcasting have underlined the efficacy of this scholarly and planning approach in terms of indicating policy pathway for sustainability transitions and thus supporting policymakers and facilitating and guiding their actions. However, as there are a number of backcasting approaches used in different domains, and the backcasting framework is adaptive and contextual in nature, it is deemed highly relevant and useful to devise a scholarly and planning approach to strategic smart sustainable city development. This paper has a fourfold purpose. It aims (1) to provide a comparative account of the most commonly applied approaches in futures studies dealing with technology and sustainability (forecasting and backcasting); (2) to review the existing backcasting methodologies and discuss the relevance of their use in terms of their steps and guiding questions in analyzing strategic smart sustainable city development as an area that is at the intersection of city (Continued on next page)
\end{abstract}

\footnotetext{
Correspondence: simoe@ntnu.no
}

Department of Computer and Information Science, Department of Urban

Planning and Design, NTNU Norwegian University of Science and

Technology, Sem Saelands veie 9, NO-7491 Trondheim, Norway 


\begin{abstract}
(Continued from previous page)
development, sustainable development, and technology development; (3) to synthesize a backcasting approach based on the outcome of the review and discussion; and (4) to examine backcasting as a scholarly methodology and planning approach by looking at its use in the Gothenburg 2050 Project, as well as to use this case to illustrate the core of the synthesized approach. The synthesized scholarly and planning approach serves to help researchers and scholars in analyzing strategic smart sustainable city development to assist planners, policymakers, and decision-makers in their endeavor to implement smart sustainable cities.
\end{abstract}

Keywords: Smart sustainable cities, Sustainability, Sustainable development, Backcasting, Forecasting, Futures studies, Strategic planning, Strategic smart sustainable city development, Scholarly and planning approach,

\section{Introduction}

The central role of cities in sustainable development is clearly reflected in the Sustainable Development Goals (SGDs) of the United Nations [75] 2030 Agenda for Sustainable Development, which is about making cities resilient and sustainable (SDG Goal 11). The defining role of cities in sustainable local and global development is well documented [28, 75]. As the engines of economic growth, cities are the world's major consumers of energy resources and significant contributors to greenhouse gas (GHG) emissions. They consume 67\% of the global energy demand and generate up to $70 \%$ of the harmful GHG emissions (e.g., [26]). Accordingly, they have increasingly gained a central position in applying the discourse of sustainable development and ecological modernization. They are seen as the most important arena for sustainability transitions because they constitute key sites of economic, environmental, and social dynamism and innovation making significant contributions to sustainable transformations and thus social change and cultural advancement. As such, they offer ideal testing grounds for new solutions spanning diverse sectors. As they are essential places where new ideas are created, tested, and advanced, many sustainable urban development frameworks and approaches reference the role of ICT in advancing the goals of sustainable development (e.g., [3-5, 12, 13, 70]). For example, the UN's 2030 Agenda for Sustainable Development sees ICT as a means to promote economic development and protect the environment, increase resource efficiency, achieve human progress and knowledge in societies, upgrade legacy infrastructure, and retrofit industries based on sustainable design principles [74, 75]. The tremendous and multifaceted potential of the smart city approach has been under investigation by the United Nations [73] through their study on "Big Data and the 2030 Agenda for Sustainable Development."

In light of the above, recent research endeavors have recently started to focus on amalgamating sustainable cities and smart cities as urban development strategies in an attempt to achieve the required level of sustainability with respect to urban operations, functions, services, designs, and policies under what is labeled "smart sustainable cities of the future" [12]. Especially, smart cities have been criticized for their lack of explicitly incorporating the goals of sustainable development (e.g., [12, 34, 43]) and sustainable cities for facing difficulties in translating sustainability into the built environment and for evaluating the extent to which different sustainable urban forms contribute to the goals of sustainable development $([16,31,37,40,78])$. Adding to these is the weak or lack of connection between the two urban development strategies, despite the proven role of ICT in supporting cities in their transition towards the needed sustainable development (e.g., [1, 19, 43]). On this note, Angelidou et al. [5] conclude that the smart city and sustainable city landscapes are extremely fragmented both on the policy and the technical levels, and there is a host of unexplored opportunities towards smart sustainable city development. The basic idea of smart sustainable cities of the future is that this holistic urban development approach seeks to explicitly bring together sustainable cities and smart cities as urban endeavors in ways that address and overcome the key shortcomings of both classes of cities in terms of their contribution to the goals of sustainable development. This can be accomplished by merging and leveraging what each class has to offer for sustainability in terms of pervasive computing and advanced ICT enabling smart cities and design concepts and planning principles guiding sustainable urban forms, with the sheer purpose of advancing sustainability in an increasingly technologized, computerized, and urbanized world [12].

Smart sustainable cities represent a manifestation of sustainable urban development as a process of change and a strategic approach to achieving the long-term goals of sustainability. Accordingly, such strategy is intended to achieve the required level of sustainability as to operational functioning, planning, and governance with the support of ICT of pervasive computing as a set of advanced technologies and their novel applications pertaining to big data analytics, context-aware computing, and other recent computing waves. Achieving the state of smart sustainable cities represents an instance of 
urban sustainability, a concept that refers to a desired (normative) state in which a city strives to retain a balance of socio-ecological systems through the strategic process of sustainable development as a desired trajectory. Urban sustainability is cast in terms of four dimensions: physical, environment, social, and economic, which should all be enhanced over the long run-given their interdependence, synergy, and equal importance. To achieve this long-term goal requires a planning framework for strategic smart sustainable city development that facilitates and contributes to the design, development, implementation, evaluation, and improvement of urban systems, including practical interventions for coordinating, integrating, and coupling urban domains, using cutting-edge technologies. This strategic endeavor should focus on replenishing resources, lowering energy use, and lessening pollution and waste levels while improving social justice, equity, stability, and safety. Accordingly, it can best be pursued through backcasting as a strategic planning approach due to its appropriateness for addressing sustainability issues (see, e.g., [22, 27, 36, 51]).

In addition, the problems that both smart cities and sustainable cities face today will increase in the future with much greater compounding affects. Consequently, policy actions for developing smart sustainable cities of the future ought to be applied, tested, transformed, disseminated, and adapted to help solve those problems. Smart sustainable cities require long-term strategic planning to overcome their particular challenges. An appropriate response to smart sustainable city development involves the analysis of several factors, including past, present, and future situations; long-term visions; formulation, implementation, and follow-up; transfer and deployment of technologies; building and enhancement of human and social capacity; and regulatory policies. These factors are intertwined and thus cannot be isolated from each other in all kinds of urban sustainability endeavors, which indeed require a system-oriented perspective to addressing environmental, economic, and social issues. Futures studies offer promising approaches to building smart sustainable city foresight, especially in the situation where the problem is complex and major change is needed. Backcasting as a scholarly methodology is well suited to any multifaceted kind of planning process (see [51]).

Envisioning smart sustainable cities as future human settlements has an obvious normative side: what futures are desired? Backcasting the preferred vision of the future has an analytical side: how can we attain this desirable future? Backcasting is a process of starting from a desirable (sustainable) future as a vision of success, then looking back to today to identify the most strategic steps or actions necessary for achieving that specified future.
Indeed, backcasting as a scholarly and planning approach is increasingly used in futures studies in fields related to urban sustainability as a formal element of future strategic initiatives and endeavors. It is viewed as a natural step in operationalizing sustainable urban development.

This paper has a fourfold purpose. It aims (1) to provide a short comparative account of the most commonly applied approaches in futures studies dealing with technology and sustainability (forecasting and backcasting), with the main focus on and the primary intent of highlighting the relevance of backcasting approach to sustainability planning as a set of complex problems; (2) to review the existing backcasting methodologies and discuss the relevance of their use in terms of their steps and guiding questions in analyzing strategic smart sustainable city development as an area that is at the intersection of city development, sustainable development, and technology development; (3) to synthesize a backcasting approach based on the outcome of the review and discussion; and (4) to examine backcasting as a scholarly methodology and planning approach by looking at its use in the Gothenburg 2050 Project, as well as to use this case to illustrate the core of the synthesized approach. The motivation for this paper is to provide guidelines and tools for the development of smart sustainable cities of the future.

This paper is organized as follows: the "Conceptual and theoretical background" section introduces, describes, and discusses the relevant conceptual and theoretical constructs that make up this study. The "Futures studies: dimensions, objectives, types, and approaches" section provides an account of futures studies, covering dimensions, aims, types, and approaches, with a focus on sustainability issues. The "Backcasting approach to strategic planning" section reviews the existing backcasting methodologies and discusses the relevance of their use in terms of their steps and guiding questions in analyzing strategic smart sustainable city development as a scholarly area that integrates city development, sustainable development, and technology development. The "A synthesized scholarly and planning approach to strategic smart sustainable city development" section synthesizes a backcasting framework as a scholarly and planning approach to strategic smart sustainable city development based on the outcome of the review and discussion. Backcasting is examined, in the "Case study: the Project Gothenburg 2050" section, by looking at its use in the Gothenburg 2050 Project. A discussion of backcasting as a useful tool for achieving urban sustainability is the object of the "Backcasting as a useful tool for achieving urban sustainability: the shaping role of political action in sustainability transitions" section. The paper ends, in the "Conclusions" section, with concluding remarks and some reflections. 


\section{Conceptual and theoretical background Smart sustainable cities}

The concept of smart sustainable cities has emerged as a result of three important global trends at play across the world, namely the diffusion of sustainability, the spread of urbanization, and the rise of ICT [12]. As echoed by Höjer and Wangel [34], the interlinked development of sustainability, urbanization, and ICT has recently converged under what is labeled "smart sustainable cities." Accordingly, smart sustainable cities represent a new techno-urban phenomenon that emerged around the mid-2010s (e.g., [12, 15]). The basic idea is to leverage the potential and ubiquity of advanced ICT in the transition towards the needed sustainable development in an increasingly computerized and urbanized world. Therefore, the development of smart sustainable cities is gaining increasing attention worldwide from research institutes, universities, governments, policymakers, and ICT companies as a promising response to the imminent challenges of sustainability and urbanization. As an amalgam of urban and technological innovations, smart sustainable cities are rapidly gaining momentum as a holistic urban development approach and thus becoming an academic pursuit and evolving into a realist enterprise across the world, not least in ecologically and technologically advanced nations [14].

The term "smart sustainable city," although not always explicitly discussed, is used to describe a city that is supported by the pervasive presence and massive use of advanced ICT, which, in connection with various urban systems and domains and how these intricately interrelate and are coordinated respectively, enables the city to control available resources safely, sustainably, and efficiently to improve economic and societal outcomes. The combination of smart cities and sustainable cities, of which many definitions are available, has been less explored as well as conceptually difficult to delineate due to the multiplicity and diversity of the existing definitions (see [15] for an overview). ITU (2014) provides a comprehensive definition based on analyzing around 120 definitions, "a smart sustainable city is an innovative city that uses...ICTs and other means to improve quality of life, efficiency of urban operation and services, and competitiveness, while ensuring that it meets the needs of present and future generations with respect to economic, social and environmental aspects." Another definition put forth by [34] (p. 10), which is deductively crafted and based on the concept of sustainable development, states that "a smart sustainable city is a city that meets the needs of its present inhabitants without compromising the ability for other people or future generations to meet their needs, and thus, does not exceed local or planetary environmental limitations, and where this is supported by ICT." This entails unlocking and exploiting the potential of ICT of pervasive computing as an enabling, integrative, and constitutive technology for achieving the environmental, social, and economic goals of sustainability due to the underlying transformational, substantive, and disruptive effects $[15,16]$. Another conceptualization of the term provided by [14] (p. 11) states: "as a dynamic, complex interplay between scientific innovation, technological innovation, environmental innovation, urban design and planning innovation, institutional innovation, and policy innovation, smart sustainable cities represent and involve inherently complex socio-technical systems of all sorts of innovation systems. Such systems, which focus on the creation, diffusion, and utilization of knowledge and technology, are of various types (variants of innovation models), including national, regional, sectoral, technological, and Triple Helix of university-industry-government relations."

As ICT permeates infrastructures, architectural and urban designs, ecosystem services, human services, and citizens' objects, we can speak of cities getting smarter as to addressing environmental, social, and economic problems, as well as providing services to citizens to improve the quality of their life $[9,12,14,15]$. Indeed, this pervasion of ICT into urban environments implies new and more extensive sources of urban data, which can provide immense possibilities to better monitor, understand, analyze, and plan smart sustainable cities to improve their contribution to the goals of sustainable development [12]. The increasing convergence of ICT of various forms of pervasive computing is increasingly seen as a way to capture further and invigorate the application demand for the many solutions for urban sustainability that emerging and future ICT can offer. The ability of computerizing urban systems and domains and hence thinking data analytically and based on context information about how to enhance their contribution to the different dimensions of sustainability constitutes an indication of the reach of the gravitational field of ICT of pervasive computing's effort to develop innovative solutions and sophisticated approaches from the ground up for smart sustainable cities of the future [14]. Therefore, the potential of monitoring, understanding, analyzing, and planning cities through advanced ICT can well be leveraged in advancing sustainability $[14,15]$. Indeed, smart cities (e.g., $[3,9])$ and sustainable cities (e.g., [12, 16]) that are engaging on the new transition in ICT are getting smarter in achieving the required level of sustainability. As complex systems par excellence, smart sustainable cities rely more and more on sophisticated technologies and their novel applications to realize their full potential and thus respond to the challenge of sustainability. The most prevalent of these technologies and their applications, which are prerequisite for realizing ICT of pervasive computing, are UbiComp, AmI, the 
IoT, and SenComp and related big data analytics and context-aware computing in relation to sustainable urban development [12]. Big data analytics and context-aware computing as rapidly growing areas of ICT are becoming of crucial importance to the operational functioning and planning of smart sustainable cities [12]. Therefore, the expansion of these computing waves is increasingly stimulating the development of different models of the smart sustainable city as urban initiatives and projects.

\section{Strategic smart sustainable urban planning}

Institutionalized in many industrialized nations since the late nineteenth century, urban planning (also referred to as city planning and urban development) is a governmental function in most countries worldwide. It is practiced on the neighborhood, district, city, metropolitan, regional, and national scales with land use, environmental, transport, local, metropolitan, and regional planning representing more specialized foci. Accordingly, urban planning is a political and technical process concerned with the development and use of land, the protection and use of the environment, the design of the urban environment, and public administration and welfare. Several notable books (e.g., [38, 45, 46, 48, 77]) have been written on the subject of urban planning (and development). They have approached it from a variety of perspectives, often combined, including physical, spatial, social, cultural, political, economic, and ecological. Urban planning is the process of guiding and directing the use and development of land, urban environment, and natural environment, as well as ecosystem and human services-in ways that ensure effective utilization of natural resources, intelligent management of infrastructures and facilities, efficient operations and services, optimal economic development, and high quality of life and well-being. In more detail, urban planning involves drawing up, designing, evaluating, and forecasting an organized, coordinated, and standardized physical arrangement and infrastructural system of a city and the associated processes, functions, and services, i.e., built form (buildings, streets, residential and commercial areas, facilities, parks, etc.), urban infrastructure (transportation, water supply, communication systems, distribution networks, etc.), ecosystem services (energy, raw material, air, food, etc.), human services (public services, social services, cultural facilities, etc.), and administration and governance (implementation of mechanisms for adherence to established regulatory frameworks, practice enhancements, policy recommendations, technical and assessment studies, etc.). The ultimate aim of urban planning is to make cities more sustainable and thus livable, safe, resilient, and attractive places. As an academic discipline, urban planning is concerned with strategic thinking, research and analysis, sustainable development, economic development, environmental planning, transportation planning, land-use planning, landscape architecture, civil engineering, policy recommendations, public administration, and urban design (e.g., [49]). Urban planning is closely related to the field of urban design, and some urban planners indeed provide designs for neighborhoods, streets, buildings, parks, and other urban areas.

The research and practice in the field of smart sustainable cities tend to focus on the identification of the urban domains that are associated with sustainability dimensions (including transport, energy, environment, land use, mobility, traffic, healthcare, education, public safety) - on the basis of big data-for storage, processing, analysis, modeling, and simulation so to develop urban intelligence functions and simulation models for strategic decision-making and enhanced insights pertaining to urban planning processes $[12,13]$. This also involves how those domains interrelate and can be coordinated and merged together for enhanced outcomes in terms of the contribution to the goals of sustainable development. The technical features of smart sustainable urban planning involve the application of ICT as a set of scientific and technical processes to land use, natural ecosystems, physical structures, spatial organizations, natural resources, infrastructure systems, socio-economic networks, and citizens' services. Recent evidence (e.g., [3, 9, $10,12,13,16])$ lends itself to the argument that an amalgamation of these strands of urban planning with cutting-edge big data analytics as an advanced form of ICT can help create more sustainable and thus livable, safe, and attractive cities. In all, the data-driven approach to urban planning is of paramount importance to strategic sustainable urban development. Besides, the functioning, management, and organization of urban systems and related processes and activities in the field of sustainable urban planning require not only complex interdisciplinary knowledge of sustainability but also sophisticated technologies and powerful data analytics capabilities.

Sustainable development goals and smart targets should be well understood with respect to their synergy and integration (see, e.g., $[1,5,9,12,13,16,19,43]$ ) in the context of city planning, a valuable force for attaining a sort of integrated objectives in the realm of smart sustainable cities. As a management and government function, city planning involves formulating a detailed plan to achieve optimum balance of demands for growth with the available resources and the need to protect the environment, or to provide and maintain a livable and healthy human environment in conjunction with minimal demand on resources and minimal impacts on the environment-by integrating urban strategies with technological innovations as well as formulating and 
implementing policy regulations and institutional frameworks. In this respect, backcasting appears to be the most appropriate planning approach into smart sustainable city development due to the complexity of the problem at hand, and the fact that different directions of development can be allowed given the wide scope and long time horizon considered.

Smart sustainable urban planning uses ICT and other means to guide and direct the use and development of land, resources, and infrastructures; the protection of the environment; and the distribution of ecosystem and human services-in ways that strategically assess and continuously improve the contribution of the city to the environmental, economic, and social goals of sustainable development. Thus, it involves a set of approaches into practically applying and effectively merging sustainability knowledge and eco-technology to the planning and development of existing and new cities. This entails working strategically towards maximizing the efficiency of energy and material resources, creating zero-waste systems, supporting renewable energy production and consumption, promoting carbon neutrality and reducing pollution, decreasing transport needs and encouraging walking and cycling, providing efficient and sustainable transport, preserving ecosystems, emphasizing design scalability and spatial proximity, and promoting livability and sustainable community $[12,13]$. ICT is of fundamental importance to attaining such goals due to its constitutive nature and transformational effects.

What is known about the relationship between urban planning interventions, sustainability, and ICT objectives is a subject of philosophical debate. This means that realizing smart sustainable cities requires making countless and integrated decisions about urban form, urban design, sustainable technologies, and governance. Regardless, this endeavor should consist in adopting a holistic approach to decision-making, a pathway that can best be pursued by employing advanced technological systems and analytical methods, thereby the need for big data technologies and related data-driven decision-making with respect to urban policy design and analysis. As noted by Angelidou et al. [5], the incorporation of the systematic use of big data in the policy development and monitoring process is a key success factor towards better policy design and implementation, with significant positive impacts on contemporary cities on multiple levels. To put it differently, new sources of urban data coordinated with urban practice and policy can be applied on the basis of the fundamental principles of data science and analytical engineering to devise powerful solutions to urban sustainability problems. Big data analytics for decision-making (basing the decisions on the analysis of big data) can be of wide use in different areas of urban planning. Indeed, big data uses are associated with optimization, control, automation, management, evaluation, recommendation, and improvement in relation to urban operational functioning, development, and governance in the context of sustainability [12]. This should constitute an integral part of the detailed plan to be formulated based on backcasting for smart sustainable city development, where consideration is typically given to a wide array of sustainability issues, such as air pollution, traffic congestion, land use, energy consumption, legislation and regulation, and social policy. Smart sustainable urban planning is gaining special importance in, and its prominence is increasing throughout, the twenty-first century, as contemporary cities are increasingly facing enormous challenges pertaining to urbanization and sustainability. As a process, it identifies the goals of sustainable development to be achieved, formulates strategies to achieve them, arranges the means and procedures required, and implements, monitors, directs, assesses, and enhances all steps in their proper sequence. This is at the core of the backcasting approach to strategic planning for the development of smart sustainable cities of the future.

\section{Strategic smart sustainable urban development}

Sustainable urban development is an approach to achieve urban sustainability. There are several approaches to sustainable urban development, one of which is the strategic one which is guided by a shared understanding of sustainability principles that embody the end goal for achieving urban sustainability. The four sustainability principles are considered as basic principles for socio-ecological sustainability as developed through scientific consensus (e.g., [36]). In the sustainable society, according to Holmberg and Robèrt [36], nature is not subject to systematically increasing:

1. Concentrations of substances extracted from the Earth's crust,

2. Concentrations of substances produced by society,

3. Degradation by physical means, and in that society...

4. People are not subject to conditions that systematically undermine their ability to meet their needs.

The purpose of articulating sustainability with scientific rigor is to make it more intelligible, more useful, and clearer for measuring, analyzing, and managing human activities within the society. From an environmental perspective, for example, to be strategic in moving towards urban sustainability requires a clear understanding of sustainability principles concerned with environmental issues, which are employed to set the minimum requirements of an environmentally sustainable city. 
Sustainability principles define an end goal for urban sustainability to plan strategically and holistically to attain socio-ecological sustainability in the city. Strategic sustainable urban development is a planned development that addresses environmental, social, and economic issues in a rigorous, meaningful, and scientific way to achieve a sustainable city. This can occur through tackling the root causes that are resulting in the current systematic decline in the potential of the city so as to help develop upstream and well-informed solutions needed to sustain the functioning of urban systems. Strategic sustainable urban development entails a backcasting from basic sustainability principles, whereby a desirable sustainable future is set as the reference point for devising and implementing strategic actions to attain that specified future, the actions needed to achieve the long-term goals of urban sustainability, and all of the other critical elements developed during the backcasting exercise. This is necessary to act proactively as well as to think strategically, on a larger scale and of future generations. Strategic sustainable urban development can be viewed as an alternative way of thinking to solve the escalating environmental problems and socio-economic issues, thereby mitigating the negative impacts of the current path of city development. As such, it seeks to guide planners, organizations, governments, and institutions to agree upon concrete ways to take action together to implement sustainable urban development on a global scale.

The concept of sustainable development has been applied to urban planning since the early 1990s (e.g., [77]). The strategic process of sustainable urban development as a desired trajectory seeks to create healthy, livable, and prosperous human environments with minimal demand on resources (energy, material, etc.) and minimal impact on the environment (toxic waste, air and water pollution, hazardous chemicals, etc.). Richardson [59] (p.14) defines sustainable urban development as "a process of change in the built environment which foster economic development while conserving resources and promoting the health of the individual, the community, and the ecosystem." In a nutshell, sustainable urban development is characterized as achieving a balance between the development of and equity in the urban areas and the protection of the urban environment. However, conflicts among the goals of sustainable urban development to achieve the long-term goals of urban sustainability are challenging to deal with and daunting to overcome. This has indeed been, and continues to be, one of the toughest challenges facing urban planners and scholars as to planning in the realm of sustainable cities. Despite sustainable urban development seeking to provide an enticing, holistic approach into evading the conflicts among its goals, these conflicts "cannot be shaken off so easily," as they "go to the historic core of planning and are a leitmotif in the contemporary battles in our cities," rather than being "merely conceptual, among the abstract notions of ecological, economic, and political logic" ([21], p. 296). Even though these goals co-exist uneasily in contemporary cities, sustainable urban development as a long-range objective for achieving the aim of urban sustainability is worthy for urban planners, as they need a strategic process to achieve the status of sustainable cities, to increase the contribution of smart cities to sustainability, and to spur the development of smart sustainable cities. As expressed by [21] (p. 9), planners will in the upcoming years "confront deep-seated conflicts among economic, social, and environmental interests that cannot be wished away through admittedly appealing images of a community in harmony with nature. Nevertheless, one can diffuse the conflict and find ways to avert its more destructive fallout." To put it differently, sustainable urban development advocates can-and ought to-seek ways to make the most of all three value sets at once. This is in contrast to keeping on playing them off against one another. With that in mind, the synergistic and substantive effects of sustainable development on forms of urban management, planning, and development require cooperative effort, collaborative work, and concerted action from diverse urban stakeholders in order to take a holistic view of the complex challenges and pressing issues facing contemporary cities.

In the context of this paper, the smart dimension of sustainable urban development is also in focus. In this regard, the strategic process of smart sustainable urban development denotes a process of change in the built environment driven by ICT and other technological innovations that seek to promote sustainable built form, environmental integration, economic regeneration, and social equity as a set of interrelated goals. In other words, to foster economic development while conserving resources and promoting the health of the ecosystem and its users requires innovative solutions and sophisticated approaches resulting from unlocking the untapped potential and transformational effects of ICT in terms of its disruptive and synergetic power given its enabling, integrative, and constitutive nature. Such process ought to be based on amalgamating the research agenda of urban computing innovation and urban ICT development with the agenda of sustainable development and urban planning, thereby justifying ICT investment and its orientation by environmental concerns and socio-economic needs within contemporary human settlements. This endeavor should in turn be supported by pertinent institutional structures and practices and policy frameworks and measures. 


\section{Futures studies: dimensions, objectives, types, and approaches}

Since the dawn of civilization, people have tried to develop methods for predicting the future. But in recent years, scientists, sociologists, researchers, and other futurists within different disciplines have developed qualitative and quantitative methods for rationally predicting the future. Rationality in this context of use signifies a recognition or awareness that many different futures are possible and that the future is far from being determined or known with absolute certainty. This is typically contingent upon the kinds of the decisions people make and action they take in the present. This paper is concerned with a backcasting approach to futures studies on smart sustainable city development, and such studies do not pretend to be able to predict the future, although assessing the probabilities of alternative futures in this regard constitutes a key aspect of the approach to studying (smart sustainable cities of) the future. Futures studies are intended to assist decision-making under uncertainty which is to be defined as indeterminacy, rather than to predict the future [27]. The backcasting approach in this context is primarily designed to help people better understand future possibilities of models of smart sustainable urban form in order to make better decisions today. Indeed, the core purpose of futures studies is to get a better understanding of future opportunities as alternatives to their differences and feasibilities. These can be employed by the aligned stakeholders in a given endeavor to challenge present systems or to influence the future. Inspire it, or adapt to the most likely one. Creating a choice of futures by outlining alternatives usually form the basis for planning. In light of this, futures studies help people to examine and clarify their normative scenarios of the future, to transform their visions, and then to develop action plans on the basis of a wide range of techniques. In the context of smart sustainable city development, they are basically used to provide an analytical framework for policy decisions in the identification of opportunities for integrating the novel applications of advanced ICT with the design concepts and planning principles of sustainable urban forms and in assessing alternative actions of high strategic potential under different conditions. The role of futures studies has become of central importance for the policy-making process in the context of urban sustainability. Such a process is characterized by increasing complexity at the macro-level as well as by decreasing the extent of conditionality at the micro-level due to the mounting autonomy of individual actors [47]. This implies that social institutions are less powerful in affecting major changes through straightforward policy responses [44].

Long-lasting and substantive transformations, including sustainability transitions, can only come about through the accumulation of several integrated smaller-scale actions associated with strategically successful initiatives and programs. They also operate at the interface of policy domains. Methods for futures studies can help to highlight such initiatives and programs and to identify such interface. In the context of city development, they can be used to illustrate what might happen to the cities in order to allow them to adapt to perceived future trends. Researchers, scientists, sociologists, and other futurists employ methods for futures studies as an attempt to manage uncertainty rather than reduce it. As such, these methods aid in dealing with this uncertainty by clarifying what the most desirable possibilities are, what can be known, what is already known, and how today's decisions and actions may play out in each of a variety of plausible futures. The effectiveness of futures studies lies in defining a broader conceptual framework for discussing the future as well as for contributing to policy formulation, transition governance, and the emergence of new possibilities. The kind of decision-making such studies seek to assist under uncertainty pertains especially to long-term decisions. In the context of smart sustainable cities, decisions are to be made in ways that reduce uncertainty about what may happen in the future in terms of urban development or analyze the effects of today's decisions taken in line with the vision of sustainability as enabled by advanced ICT in the future.

Futurists often divide the purpose of futures studies as assessing the probable, imagining the possible, and deciding on the preferable. As pointed out by Banister and Stead [7], futures studies can be classified based on the three modes of thinking about the future:

- Possible futures (what might happen?): Scenario studies as descriptions of possible future states and their developments are included in this category [20].

- Probable futures (what is most likely to happen?): This category includes forecasting studies, which are characterized by a predictive nature and mainly focused on historical data and trend analysis.

- Preferable futures (what we would prefer to happen?): This category is of relevance to futures studies dealing with urban sustainability, as it involves studies focusing on normative or desirable futures, such as backcasting and normative forecasting.

Several authors have elaborated on futures studies in relation to sustainability. Dreborg [27] identifies four different types of futures studies in connection with sustainability, namely:

- Directional studies which investigate different economics and other measures in the short term 
that will probably work in the right direction towards sustainability.

- Short-term studies which take immediate official goals as a starting point or a small step towards sustainability and attempt to find means of achieving them.

- Forecasting studies which usually apply to a longterm perspective, but restricted presumptions of the possibilities of major change make this approach fail to reach sustainability.

- Alternative solutions and visions where the development of future (normative) scenarios as desirable futures allow them to be explored by using backcasting where the results describe a desirable future with criteria for sustainability providing the systemic framework for change.

There is no consensus on a single classification of futures studies or a guide for the application of the most suitable approaches to futures studies. Most methods for futures studies focus on one or two of these goals: assessing the probable, imagining the possible, and deciding on the preferable (e.g., [47]). Futures studies on smart sustainable city development are concerned with deciding on the preferable in terms of how to prefer the development of such city to play out. In this regard, visioning techniques may provide information about the preferable as a result of visioning: the action of developing a preferred plan, goal, or vision for the future. They can also tell us about the possible as a result of brainstorming over a range of alternatives if we happen to focus on both the preferable and possible as goals. Further, beyond any kind of classification and focus, the researcher's worldview and aim are the most important criteria that determine how a futures study can be developed. Researchers will almost always need different methods to carry out their futures studies.

Being the most suitable methodological framework or planning approach to be pursued in futures studies dealing with urban sustainability, the backcasting approach is prescriptive (normative) by focusing on what smart sustainable cities of the future should be. Generally, prescriptive methods for futures studies try to aid people in clarifying their values and preferences so they can develop visions of desirable futures. Indeed, backcasting allows researchers to understand what they would prefer the future to be and then take the appropriate (or necessary) steps to create that preferred future. Methods for futures studies are also descriptive (extrapolative) in the sense of describing what the future will be or could be in an objective way. While many futurists strive for objectivity, most methods for futures studies as part of qualitative inquiry rely on subjective human judgment. Nevertheless, various tools have been developed and applied to mitigate such judgment through encouraging collective judgment, generating ideas to produce different judgments, and identifying discrepancies between competing views on the future, as well as substantiating consistencies and inconsistencies among and within such views.

There might be as many approaches to futures studies as futurists since futurists develop different ways to look ahead or envision the future. But some consensus in this regard is evolving. According to Chatterjee and Gordon [25], futures studies can be categorized on the basis of the context that is being studied in terms of simplicity and complexity. Specifically, if the context is predictable and largely controllable, then a planning approach such as forecasting may be appropriate, and if it is unpredictable and uncertain, an alternative approach such as scenario planning is more suitable [25]. Another consensual perspective among futurists is the need to employ multiple approaches to address most futures problems. In this paper, the intent is to devise or craft a backcasting as a planning method for smart sustainable city development, complemented by insights drawn from trend analysis and scenario planning. There is an argument that supports the idea of developing future research programs that integrate various approaches to futures studies to gain much greater insight than relying on a single approach. There are a number of different approaches to strategy analysis and future analysis that investigate what will, could, or should happen in the future that are in their application not mutually exclusive, including, but not limited to, cyclical pattern analysis, trend analysis, forecasting, visioning, and scenario planning, in addition to backcasting and forecasting. These are briefly presented below.

\section{Cyclical pattern analysis}

This futures study method is closely related to trend analysis. Many environmental, economic, and social phenomena seem to operate in cycles. It uses cyclic or recurring patterns in the form of waves, bursts, epochs, and episodes to anticipate future developments in various domains, such as city development, environmental change, public policy, and economic/financial system.

\section{Trend analysis}

A trend denotes a pattern of change over time in some phenomena of importance and relevance to the observer. As a common futures study method, trend analysis involves the use of a variety of techniques based on historical data. Quantitative trend analysis is often applied to areas involving solid and large historical data. Its key issue lies in the propensity to accept their results as a kind of truth about the future rather than simply a starting point for discussion [7]. Such analysis remains most 
suitable for projecting forward in a stable or nonlinear system.

\section{Technological forecasting}

Forecasting is used to predict the most likely future, projected forward over a specific time horizon (e.g., coming weeks, months, or years) based on the previous or current trends. Technological forecasting has its own concepts, techniques, and practitioners, representing a distinct endeavor within futures studies. One of the subject areas where forecasting is mostly applied is ICT development. Within the framework of technological development, forecasting concerns "the extrapolation of developments toward the future and the exploration of achievements that can be realized through technology in the long term" ([39], p. 503).

\section{Visioning}

Visioning is the action of developing, or the process of intensely making images of, the desired future (plans, goals, objectives, outcomes, etc.) sufficiently real and compelling to act as a stimulus or spur to the present action. It also refers to the fact of seeing visions. As such, it can be carried out by an individual or a group of people. The importance of seeing visions of the future, which usually materialize subsequent to new scientific discovery and its technological applications, lies in that these visions "have the power not only to catch people's minds and imaginations but also to inspire them into a quest for new possibilities and untapped opportunities and to challenge them to think outside common mindsets" ([11], p. 3).

\section{Scenario planning}

Scenarios are about making stories about the future and usually have more specific detail than backcasting. They represent a series of events that we envision or imagine happening in the future. Visionary scenarios are part of everyday thinking in that it is filled with some ventures into the unknown or mysterious world of the future, tomorrow, next week, next year, or next decade. The more elaborate scenarios (e.g., a generation of simulation games for policymakers combining known facts about the future with key driving forces identified by considering environmental, economic, social, political, and technological trends) are usually developed by professional researchers (or groups of analysts) working for government agencies in relation to different domains or for organizations and institutions.

For a detailed, descriptive account of the above approaches, which can be combined in futures studies, the interested reader can be directed to Bibri [12]. The backcasting approach, which is the focus of this paper, is addressed separately (and together with forecasting) in more details in the next section.

\section{Backcasting approach to strategic planning Historical origins and characteristic features}

The term "backcasting" was coined by Robinson [62] in the description of the policy analysis approach. The backcasting approach was originally developed in the 1970s as an alternative to traditional energy forecasting and planning and employed as a novel analytical tool for energy planning using normative scenarios. Backcasting studies concerned with energy dealt particularly with the so-called soft energy policy paths, characterized by the development of renewable energy technologies and a low-energy demand society [57]. At the time, such studies emerged as a response to regular energy forecasting, which was mainly based on trend extrapolation and projections of energy consumption, with a focus on large-scale fossil fuel and nuclear technologies. By developing an energy backcasting approach, the focus became analysis and deriving policy goals [62]. Around the 1990 s, a few years after the inception of sustainable development, the emphasis on backcasting shifted towards the identification and exploration of sustainability solutions in Sweden [27], Canada [64], and the Netherlands [76]. Such solutions pertain to a wide range of topics, including transportation and mobility [8], sustainable technologies and sustainable system innovation [76], sustainable household [30, 55], transforming companies into sustainable ones [35], sustainable urban design [51], sustainable transportation systems [2, 32, 65], and sustainable city development [22]. In light of these endeavors, it has been corroborated that the distinctive characteristics of backcasting as a planning approach make it especially appropriate for sustainability applications (e.g., [27, 35, 36]). This has to do with the idea of taking a range of sustainable futures as a starting point for analyzing their feasibility and potential, as well as possible ways of attaining those futures (e.g., [56]). For a more detailed overview of the past and present applications of backcasting, the interested reader can be directed to Quist and Vergragt [57].

Backcasting is concerned with how desirable futures can be created and attained rather than what future states of affairs are likely to occur. In other words, backcasting is not concerned with predicting the future; rather, it is a strategic problem-solving framework, in the quest for the answer to how to reach specified outcomes in the future. This involves finding ways of linking goals that may lie more than a generation in the future to a set of steps performed now and designed to achieve that end. Therefore, backcasting is used in cases when it is desired to actively dictate a future outcome rather than merely predicting it. In backcasting, one envisions a 
desirable future endpoint and then works backward to determine what programs would be required to attain that specified future or to construct a plausible causal chain leading from here to there. In more detail, backcasting as closely related to scenario planning involves an imaginary scenario moving backwards in time in as many different stages as are considered necessary as to connecting the future to the present to uncover the mechanism through which the present actions could lead to attaining that particular future scenario. Robinson [63] (p. 823) defines backcasting as a normative approach which works "backwards from a particular desired endpoint to the present in order to determine the feasibility of that future and what policy measures would be required to reach that point."

In general, the backcasting approach is applicable in futures studies dealing with the fundamental question of backcasting, which involves the kind of actions that must be taken to achieve a long-term goal. In a more specified way, as stated by Tinker [71], "if we want to attain a certain goal, what actions must be taken to get there?" Here, backcasting means to look at the current situation from a future perspective. After envisioning a successful outcome in this future scenario then comes the question of what can be done today to achieve that outcome. This enables us to ensure that strategies and actions are in the direction we want to head. Accordingly, smart sustainable cities as future desired conditions are envisioned, and appropriate actions and strategies are then defined to attain those conditions. Envisioning such cities has a normative side in terms of what future is desired, and backcasting the preferred vision of the future has an analytical side in terms of how this desirable future can be attained. In urban sustainability, planning is about figuring out the "next steps" which are quite literally the next concrete actions to undertake. Next steps are usually based on reacting to the present circumstances, creativity, intuition, and common sense but also (conceivably) are still aligned with the future vision and direction. A next step question of relevance to futures studies dealing with smart sustainable city development would be, for example, "To better monitor, understand, analyze, and plan sustainable urban forms to strategically assess, improve, and sustain their contribution to the goals of sustainable development, what is the very next thing we have to do?" Important to note, though, is that researchers in backcasting should not get obsessed with the next steps without considering how aligned they are with what they ultimately aim to achieve. Indeed, in the specific case of sustainability, it is as crucially important to undertake the first steps as to have lofty visions, thereby sustaining momentum by explicit, shared vision of success and being able to use that to guide the next steps.
Furthermore, since the notion of smart sustainable cities in this case is more a vision/image of the future than a reality, it is per definition normative, implying a certain desired view on the city within ecologically and technologically advanced nations. By the same token, the backcasting approach is normative in the sense of establishing and deriving from an evaluative norm or a standard for making judgments about outcomes. Concerned with human societies, normativity is the phenomenon of designating some desirable or permissible actions. Many researchers tend to restrict the use of the term "normative" to the evaluative sense $[17,18]$. In relation to backcasting, in consultation exercises as part of the normative-oriented visionary model of scenario writing, further insights can be gained by comparing different normative scenarios arrived at or generated by different stakeholders.

\section{Backcasting versus forecasting}

Backcasting stands out as an alternative to traditional forecasting [63]. Backcasting approaches the challenge of discussing the future from the opposite direction of forecasting [36]. Forecasting is the process of predicting the future based on monitoring and analyzing the current trend, that is, making statements about the future based on explicit or implicit assumptions drawn from the present situation in terms of observed trends. In other words, it starts the planning procedure from today's situation and projects today's trends and realistic solutions into the future [27]. This is commonly used in futures studies dealing with technological development and smart cities in the sense of defining steps that are merely a continuation of the present developments extrapolated into the future (e.g., urban computing). As explained by [39] (p. 503), "Within the framework of technological development, "forecasting" concerns the extrapolation of developments towards the future and the exploration of achievements that can be realized through technology in the long term. Conversely, the reasoning behind "backcasting" is: on the basis of an interconnecting picture of demands technology must meet in the future-"sustainability criteria" - to direct and determine the process that technology development must take and possibly also the pace at which this development process must take effect. Backcasting [is] both an important aid in determining the direction technology development must take and in specifying the targets to be set for this purpose. As such, backcasting is an ideal search toward determining the nature and scope of the technological challenge posed by sustainable development, and it can thus serve to direct the search process toward new-sustainable-technology." This is of high relevance to smart sustainable cities with regard to the interconnecting picture of demands such cities must meet in the future through integrating ICT and 
sustainability to direct and determine the process that urban development must take and also the pace at which such development must take effect. This perspective differs from what tends to be common in the framework of smart city development in terms of forecasting which concerns the extrapolation of ICT developments towards the future and the exploration of achievements enabled by innovative solutions that can be realized through ICT in the long term (e.g., big data analytics).

According to Dreborg [27], backcasting is an approach to facilitating discovery, which is different from the more commonly applied forecasting approach. A significant difference between the two approaches is in the attitude taken towards uncertainty [27]. As further elucidated by [47] (pp. 18-19), "in the forecasting approach, the uncertainty is usually treated in terms of sensitivity of the model results to variations in external variables. The futures studies of forecasting have an idea to figure the future out what will really happen in order to permit society...to adapt to the more or less inevitable trends. In the forecasting approach, it is impossible to predict our own future decisions to the extent that they are influenced by future knowledge. They often are a total causal model. The backcasting approach takes into account the indeterminacy of the future and tries to define a broader conceptual framework for discussing the future; the study is less vulnerable to unforeseen change. This kind of studies may give an impulse for new knowledge." Further, Dreborg [27] distinguishes between backcasting studies and forecasting studies at different levels, as illustrated in Table 1. However, Höjer and Mattsson [33] suggest that backcasting and forecasting are complementary.

In all, backcasting is a way of constructing a desirable future, whereas forecasting is a way of predicting a likely future state of affairs. Of importance to underscore in this regard is that in a backcasting process, a desirable future is the starting point when constructing the strategy, while in a forecasting process, the present trends and situations are key factors [65], see Fig. 1 for a comparison of the backcasting approach with the forecasting approach in a sustainability framework.

\section{The relevance and purpose of backcasting as a scholarly methodology for strategic smart sustainable city development}

Qualitative research involves a range of approaches into data collection and analysis that researchers typically rely on to investigate a wide range of sustainability issues related to the physical, environmental, technological, economic, and social dimensions of the city, or a combination of these. The choice of any qualitative approach depends largely on what the researcher intends to investigate. In the context of futures studies dealing
Table 1 Backcasting and forecasting five levels

\begin{tabular}{lll}
\hline & Backcasting & Forecasting \\
\hline 1. & Causality and teleology & Causality \\
view & Partial indeterminacy & Determinism \\
& Context of discovery & Context of \\
2. Perspective & Societal problem in & Dominant trends \\
& need of solution & Likely futures \\
& Desirable futures & Possible marginal \\
& Scope of human choice & adjustments \\
& Strategic decisions & How to adopt \\
& Retain freedom of action & trends \\
3. Approach & Define interesting futures & Extrapolate \\
& Analyze consequences, and & trends into the \\
& conditions for these futures to & future \\
& materialize & Sensitivity \\
& & analysis \\
& Partial and conditional extrapolations & Various \\
4. Method & Highlighting interesting polarities & econometric \\
& and technological limits & models \\
& & Various \\
& & mathematical \\
& & algorithms \\
& &
\end{tabular}

Source: Dreborg [27]

with strategic smart sustainable city development, backcasting as a problem-solving and planning approach is well suited to be adopted as a methodological framework for scholarly research-e.g., to investigate and analyze the development of a future model of the smart sustainable urban form (e.g., [12]).

In terms of its practical applications, backcasting as a scholarly and planning approach is increasingly used in futures studies in fields related to urban sustainability (e.g., $[47,51])$ as an alternative to traditional planning approaches and a formal element of future strategic initiatives. This is of high relevance to smart sustainable city development as an area that involves both domains [12]. The complexity of smart sustainable city planning, due to the current trends and actions being part of the problem, highlights the importance of applying the backcasting approach to have an informed vision of specific goals in order to strategically deal with potential trade-off among different decisions and actions. In this line of thinking, backcasting from system conditions of sustainability (or sustainability principles) is a key concept of the "Framework for Strategic Sustainable Development" pioneered by Karl-Henrik Robèrt, founder of The Natural Step, an international nonprofit organization dedicated to applied research for sustainability, in cooperation with a global academic Alliance for Strategic Sustainable Development which links universities which cooperate with industries and businesses. Backcasting from sustainability principles is the primary context in which The Natural Step Framework and Strategic Approach to Sustainable Development become so powerful.

In recent years, backcasting has become the most commonly applied approach to long-term futures studies on 


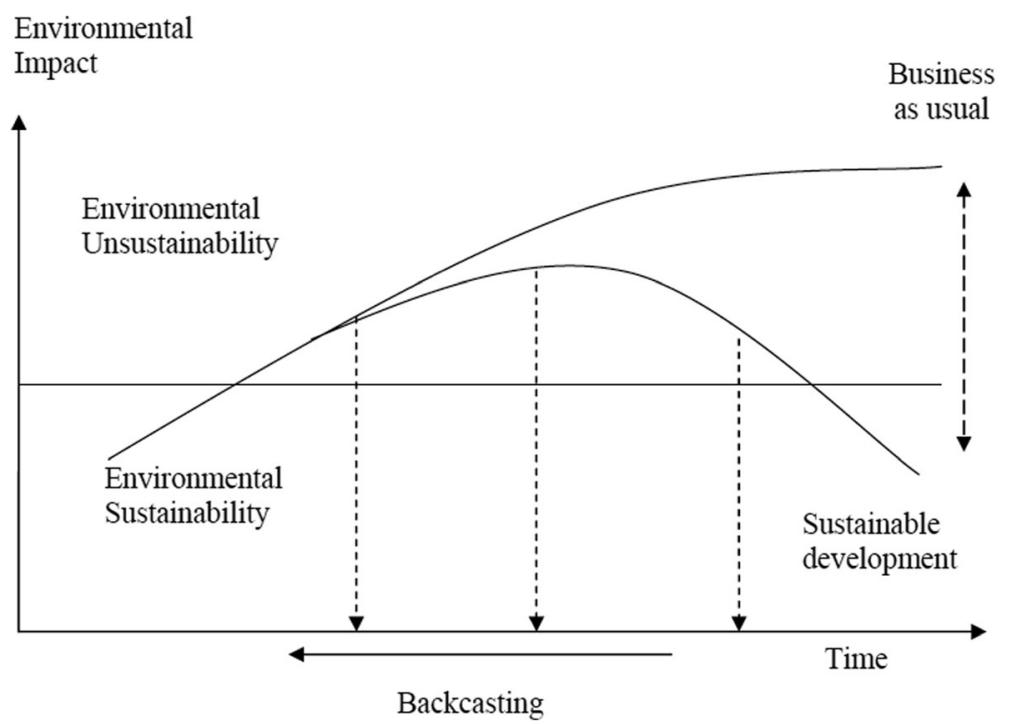

Fig. 1 Backcasting and forecasting approaches in a sustainability framework. Source: Banister [6]. Figure 1 summarizes the backcasting approach in comparison with the forecasting approach in a sustainability framework

sustainable development, thereby their appropriateness for strategic smart sustainable city development. Researchers working within various urban domains as well as within the field of smart cities and sustainable cities have endeavored to understand and act in relation to sustainable development by describing visionary (normative) scenarios of a long-term future and justifying their potential realization on the basis of established theories and academic disciplines and discourses in conjunction with in-depth analyses of case studies (i.e., strategies, projects, programs, and successful practices) in a bid to stimulate an accelerated movement towards urban sustainability. This implies that a large body of research within the field of smart sustainable cities is being, and will be, founded on long-term futures studies of different sorts. One strand of such studies concerns itself with the way such cities amalgamate sustainable development goals and smart growth targets in an integrated approach due to the synergetic and disruptive effects of emerging and future ICT, particularly on urban operational functioning, management, and planning, that are required for future forms of urban sustainability. The evolving body of futures studies in this direction constitutes a strategic resource for understanding the untapped potential of advanced ICT and its enabling, integrative, and constitutive nature for advancing urban sustainability. This involves the identification of the interconnections, relationships, and complexities associated with spatial and temporal scales in relation to urban analytics and planning using big data analytics for assessing, improving, and sustaining the contribution of smart sustainable cities to the goals of sustainable development.

The backcasting approach to strategic planning aids in determining the direction smart sustainable city development must take and in specifying the targets to be set for this purpose. As such, it represents a quest for identifying the nature and scope of the issues and challenges posed by the existing models of sustainable urban forms. And hence, it serves to direct this quest towards smart sustainable cities of the future. In other words, it sets the conditions for the creative tension that motivates the gap between the existing models of sustainable urban forms (the current reality) and smart sustainable cities (the future potential).

The analysis part will be done by studying cases using the backcasting approach such as sustainable city and smart city strategies, projects, and initiatives, with a particular focus on the design concepts and planning principles of sustainable urban forms and the novel applications of ICT of pervasive computing for sustainability (see [12] for a detailed account). The development part will be done by combining the results from the analysis with insights on how sustainability criteria can be formulated, especially in relation to the goals of sustainable development and what it means for a smart sustainable urban form as a process-oriented development approach to work with such criteria.

The purpose of backcasting studies in this regard is to create knowledge that can be used to guide complex urban transitions towards sustainability in an increasingly computerized and urbanized world. The end result thereof is alternative visions/images of the future, thoroughly analyzed as to their feasibility, potential, and consequences. In this respect, the process of backcasting involves establishing the description of a very definite and specific future situation in the form of principles and well-designed goals-i.e., how smart solutions for 
sustainability and sustainable urban forms' design concepts and planning principles can be integrated in the form of programs that must be supported by policy measures. A normative scenario can be defined, and then a step-wise back move in time is done from that scenario to the present in order to determine the necessary decisions and actions pertaining to urban planning, urban technology, and urban policy that must be taken at critical points if that scenario is to be attained.

In this particular context, backcasting planning can be viewed as changing mindsets about the way sustainable urban forms can function and be understood, monitored, analyzed, planned, and developed, prior to formulating specific strategies. Backcasting is explicitly intended to suggest the implications of various desirable futures, chosen on the basis of criteria defined externally to the analysis (e.g., sustainability and ICT as of desirability) rather than on the basis of their likelihood (see [47]). Additionally, Dreborg [27] argues that backcasting is particularly useful when:

- The problem to be studied is complex, and there is a need for major change

- The dominant trends are part of the problem

- The problem to a great extent is a matter of externalities

- The scope is wide enough, and time horizon is long enough to leave considerable room for deliberate and different choices and directions of development.

The above is indeed of high relevance to the research problem of strategic smart sustainable city development. In complex systems like smart sustainable cities, and with complicated endeavors like sustainable development, backcasting is an effective approach to align various measures with each other, and thus to ensure that each activity is the logical platform for the next one, to draw on Robèrt [60]. In addition, backcasting is well suited for long-term problems and long-term sustainability solutions thanks to its normative and problem-solving character [27]. Furthermore, as pointed out by Robinson [63], backcasting is not necessarily only about how desirable futures can be created and attained but also about analyzing the extent to which undesirable futures can be responded to or avoided. Overall, backcasting studies must reflect solutions to a specified social problem in the broader sense [27].

Projecting a transformative urban change that challenges existing assumptions for sustainable urban forms as a problem of significant complexity with a long enough time horizon to allow for making determined choices is the key role of backcasting in the futures studies dealing with smart sustainable city development [12]. It is used to identify signals of sustainable urban change and also to determine short-term planning and policy goals that might facilitate long-term outcomes envisioned in future scenarios. In all, to backcast is mostly of pertinence when the future is uncertain, and our actions are likely to influence, inspire, or create that future. To note, given that there is often greater uncertainty over what may happen in longer time frames, the future vision may usefully be described or defined using principles or well-designed goals rather than specifics.

\section{The multiplicity and adaptation of methodological frameworks for backcasting}

In every situation, there is a way for many individuals, teams, and organizations to get clear on an agreed future vision of success to which all efforts can be directed and focused. The literature shows that there are a number of methodological frameworks applied in backcasting. The backcasting framework is adaptive in nature within its steps and thus guiding questions based on the specific context (academia, industry, government, etc.) under which it is applied, the stakeholders involved, and the complementary methods to be used (trend analysis, forecasting, scenario planning, visioning, etc.). The result is a process that can be considered more as a set of guiding principles and tools than as a strict adherence to the application of the approach as a process encompassing all the steps involved in a given backcasting methodology by soundly including the full set of guiding questions. Worth noting, the terms backcasting approach and backcasting methodology are differentiated in the literature. Quist [53] clearly elaborates in his work that "backcasting approach" should be used to describe general and more abstract terms, whereas "backcasting methodology" should be applied in such concrete cases. Regardless, there are several backcasting approaches or methodologies, and while these differ in their steps and thus guiding questions, they do converge on the essentials (as discussed below). Fundamentally, a backcasting study involves four steps [33], namely:

1. The setting of a few long-term targets

2. The evaluation of each target against the current situation, prevailing trends, and expected developments

3. The generation of images of the future that fulfill the targets

4. The analysis of images of the future in terms of feasibility, potential, and path towards images of the future [2].

Robinson's [63] backcasting approach uses such methods as social, economic, and environmental impact analysis; scenario construction methodologies; and system analysis, and modeling The Natural Step (TNS) 
backcasting framework for sustainable development [35, 61] relies on such methods as creativity techniques, strategy development, employee involvement, and employee training. The Sustainable Technology Development (STD) backcasting approach [76] employs such methods as stakeholder analysis, employee training, problem analysis, technology analysis, and construction of future visions.

The key assumptions of Robinson's backcasting approach include the following:

- Criteria for social and environmental desirability are set externally to the analysis

- Goal-oriented

- Policy-oriented

- Design-oriented

- System-oriented.

The key assumptions of the TNS backcasting approach encompass the following:

- Decreasing resource usage

- Decreasing emissions

- Safeguarding biodiversity and ecosystem

- Efficient utilization of resources in line with the equity principle.

The key assumptions of the STD backcasting approach include the following:

- Sustainable future need fulfillment

- Factor 20

- Time horizon of 40-50 years

- Co-evolution of technology and society

- Stakeholder participation

- Focus on realizing follow-up.

Backcasting can be described as an innovative participatory foresight approach to sustainability through the construction of normative sustainable futures by a variety of stakeholders [56]. The development towards participatory backcasting utilizing inputs from a broad range of stakeholders and discussions among them took place first in the early 1990s, a few years after the inception of sustainable development, and continued till today. During this period, backcasting has indeed been focused on the identification and exploration of sustainability solutions regarding a wide range of topics and also shifted towards achieving implementation and follow-up. However, several questions have recently been raised concerning the adaptation of the complex transdisciplinary and participatory backcasting approach so that it can be suited to different projects or research endeavors. The factors triggering its adjustment accordingly involve the diversity in interests, mental frameworks, and resources as well as the presence of dependencies between stakeholders and power issues among them in a regular backcasting project [56]. As a scholarly methodology for strategic smart sustainable city development, the backcasting approach is not fully participatory, as it does not directly involve stakeholders from different societal groups. Nonetheless, it is informed by the knowledge of many experts, scholars, and scientists from relevant fields and professional domains, expressed in the literature (i.e., case studies, strategies, projects, and practices pertaining to smart sustainable city development). Backcasting projects with stakeholders in a real-life setting do involve stakeholders due to their position or influence in the field, their interests and stakes being at play, or their relevant knowledge about the problems and possible solutions; yet, they are not responsible for the application of the overall approach (or specific methods and tools) and its key feature of working from normative scenarios (desirable sustainable future visions) to activities and action agendas, so these are rather the responsibility of the facilitators [56]. However, the fifth goal concerning the stakeholder support, learning, and commitment for implementation (see [56] for the full list of goals below) can still be realized in the context of smart sustainable city development given its benefits and underpinning foundations with regard to sustainability and ICT as influential theories and powerful large-scale societal discourses. But the backcasting exercise should be conducted by city governments or powerful urban actors as a group of societal stakeholders rather than individual academic researchers or scholars. The goal pertains to making strategic action plans and considering the potential stakeholder support and commitment, ways to stimulate follow-up by stakeholders, and the instruments and measures that could support such activities [56].

As regards to the perspective on stakeholder involvement in futures studies where backcasting can be used as a scholarly methodology, the idea is to incorporate the views, assumptions, claims, and arguments (a set of reasons given in support of ideas, theories, and/or actions) of different experts, scholars, and scientists in the field of smart cities and sustainable cities in the analysis and development of future models for smart sustainable city. In addition to gathering data and facts, a range of stakeholder recommendations concerning such models and their feasibility and potential will be considered and included. Another emphasis of futures studies on smart sustainable city development is to provide suggestions for government, policymakers, and research bodies.

\section{Methodological frameworks for backcasting-participatory backcasting}

Several methodological frameworks for backcasting have been developed and applied in relation to sustainability. 
Phdungsilp [51] compares three backcasting methodologies, namely Robinson's, TNS, and STD, as illustrated in Table 2.

As an explicitly normative and design-oriented, Robinson's approach aims to explore the implications of alternative development paths. However, it gives no standard recipe for generating scenarios, only some helpful guidelines and tools. The scenarios are evaluated in terms of socio-economic, physical, and technological feasibility and policy implications. Iteration of scenarios is usually required to resolve physical inconsistencies as well as to mitigate adverse economic, social, and environmental impacts that are revealed in the analysis. From a critical perspective, the approach puts a strong focus on technical analysis and policy recommendations, and neither specifies who is responsible for setting the criteria and future goals and how this will be done nor includes stakeholder participation.

In Sweden, backcasting has been elaborated as a methodology for strategic planning towards sustainability, which has become known as the TNS Framework. Backcasting has been advocated and popularized by Karl-Henrik Robèrt and thoroughly described by Holmberg [35]. Underlying the TNS approach is the way of thinking that the future itself cannot be predicted, but by viewing the physical principles of the ecosystem, a set of principles can be set to describe the future sustainable situation. This is based on four system conditions that should be simultaneously valid in a sustainable society [60].

The STD approach relates to a Dutch government program, which focuses on achieving sustainable need fulfillment in the distant future. It involves a broad stakeholder participation, future visions or normative scenarios, and the use of creativity to reach beyond existing mindsets and paradigms [53]. It has also been used for the integration of spatial functions.

There are some similarities and differences between the above three backcasting approaches. The overall approach provides a framework consisting of steps in which various types of methodologies can be applied. They all contain analytical methods and design methods. They moreover contain steps in which future visions or normative scenarios are constructed, and the current situation is analyzed. Regarding the differences, Robinson's approach and the TNS approach do not contain a separate backcasting step. They reserve the term backcasting for the overall approach. By contrast, the STD approach contains a separate backcasting step. Additionally, the TNS and the STD approaches contain steps dealing with operational aspects of implementation and follow-up, strategies, and agenda setting. Participatory methods are found in the TNS and STD approaches but not in the case of Robinson's backcasting approach. In futures studies associated with strategic smart sustainable city development, the intent is to devise a generic methodological framework for backcasting planning by synthesizing Robinson's, the TNS, STD, and other approaches, which is the object of the next section. This scholarly methodology and planning approach could then be used to analyze and develop future models for the smart sustainable city.

A methodological framework for backcasting can be synthesized based on different approaches (including $[23,36,54,57])$ and encompasses five steps, namely:

1. Domain and demographics-involves the clarification of the issues of the current state and the identification of the areas to be targeted and of all key and relevant stakeholders

2. Future vision-entails the definition and description of a desirable future or normative scenario in which the problems and issues identified have been solved by meeting the stated objectives

3. Steps-consists of developing possible steps (as well as addressing their feasibility) on how to reach the future vision from the present, addressing various dimensions (i.e., technological, social, cultural,

Table 2 Comparison of three backcasting methodologies

\begin{tabular}{|c|c|c|}
\hline Robinson's methodology & TNS methodology & STD methodology \\
\hline $\begin{array}{l}\text { 1. Determine objectives } \\
\text { 2. Specify goals, constraints, } \\
\text { and targets, and describe } \\
\text { present system and } \\
\text { specify exogenous variables } \\
\text { 3. Describe present system } \\
\text { and its material flows } \\
\text { 4. Specify exogenous variables } \\
\text { and inputs } \\
\text { 5. Undertake scenario } \\
\text { construction using } \\
\text { the specified goals and constraints } \\
\text { 6. Undertake } \\
\text { scenario impact analysis }\end{array}$ & $\begin{array}{l}\text { 1. Define a framework and } \\
\text { criteria for sustainability } \\
\text { 2. Describe the current situation } \\
\text { in relation to that framework } \\
\text { 3. Envisage a future sustainable } \\
\text { situation } \\
\text { 4. Find strategies for sustainability }\end{array}$ & $\begin{array}{l}\text { 1. Strategic problem orientation } \\
\text { 2. Develop sustainable future vision } \\
\text { 3. Set out alternative solutions } \\
\text { 4. Explore options and identify bottlenecks } \\
\text { 5. Select among options and set up action plans } \\
\text { 6. Set up co-operation agreements } \\
\text { 7. Implement research agenda }\end{array}$ \\
\hline
\end{tabular}

Source: Phdungsilp [51] 
political, institutional, and organizational) that require consideration

4. Analysis-involves assessing the developed future alternative, with the goal of creating an actionable plan while mitigating predicted threats and risks to successful implementation

5. Implementation-is about establishing an action plan and putting it into motion while addressing the responsibilities of the key stakeholders concerned with the implementation of the results.

Quist and Vergragt [57] and Quist [52] distinguish several varieties of backcasting and put them into a methodological framework for participatory backcasting consisting of five steps, namely:

1. Strategic problem orientation

2. Specification of external variables

3. Construction of future visions or scenarios

4. Backcasting: backward-looking analyses

5. Elaboration and defining follow-up and an action agenda.

In the first stage, normative assumptions are defined, and goals are specified in relation to sustainability. The backcasting process starts off with defining the objectives with a description of the aim of the analysis in terms of its spatial, substantive, and temporal scope alongside the number and type of scenarios. The objectives are then translated into specific goals, constraints, and targets for scenario analysis and exogenous variables.

In the second stage, the exogenous variables are identified to describe the system not incorporated within the backcasting itself. The relevance of describing the broader context within which the analysis will take place lies in defining the different external elements that could act as direct inputs to the scenario analysis.

In the third stage, which is the core one of the backcasting process, the scenarios are constructed. This stage includes the development of future scenarios and the analysis of the future situation at the end and midpoints as well as the internal consistency of the scenario.

The fourth stage involves both design and analysis. It undertakes impact analysis by consolidating scenario results, which involves environmental, social, and economic effects and the consistency between the specified goals and scenario outcomes.

The fourth stage is usually linked to the policy process which constitutes part of the fifth stage. This aims at determining the political actions and institutional responses that are required for the implementation of the scenarios and the policy measures implied in those actions and responses.
Although this method is generally depicted stepwise and gives the impression that it is linear, it is definitely far from it. There is also a mutual influence between the different steps of the participatory backcasting approach following one another, and iteration cycles are likely to occur.

Of relevance to underscore is that Quist et al. [56] remove the second step but add another one as a fifth step: embedding of results and generating follow-up.

According to Quist and Vergragt [57], four groups of tools and methods can be distinguished within the participatory backcasting approach, namely:

1. Participatory tools and methods which are useful for involving stakeholders and for generating and guiding interactivity among them

2. Design tools and methods for constructing scenarios and for designing and elaborating stakeholder interaction processes

3. Assessments of scenario and design such as environmental assessments and economic analysis and also evaluation of social processes in the backcasting project and stakeholder analysis

4. Overall management, coordination, and communication tools and methods.

Moreover, different goals can be distinguished that are not necessarily all present in a particular backcasting project. Possible goals for backcasting studies include [56]:

- Generating normative alternatives for the future and analyzing their opportunities, potentials, environmental benefits, and other effects

- Putting attractive normative scenarios on the agenda of relevant societal arenas

- A follow-up agenda containing activities or actions for the different stakeholders involved in, or contributing to, bringing about the desirable future and its implementation

- Stakeholder learning with respect to the alternatives, the effects, and the opinions of other stakeholders

- Stakeholder support in regard to vision, design, analysis, and commitment to the follow-up agenda.

In sum, the key components of the participatory backcasting include [52, 57]:

1. The construction and use of desirable normative scenarios and goals.

2. Broad stakeholder participation and stakeholder learning (on the level of paradigms and values)

3. Combining process, participation, analysis, and design using a wide range of methods within the overall backcasting approach. 
The participatory backcasting approach uses a set of questions for each step. Table 3 illustrates these questions in a backcasting project where step 4 "elaboration and defining action agenda and follow-up" and step 5 "embedding and initiating or stimulating follow-up activities" are combined due to the limited time and changes in stakeholder involvement. Specifically, as suggested by [56] (p. 872), "implementation and embedding is changed into making a follow-up proposal, sketching a rough development and implementation trajectory, and analyzing what could or should be the contribution of different stakeholder groups."

\section{A synthesized scholarly and planning approach to strategic smart sustainable city development} Premises and assumptions underlying the synthesis

The synthesized scholarly methodology and planning approach to strategic smart sustainable city development is primarily intended to be used by researchers and scholars working within academia and research institutes, who are particularly concerned with the investigation and analysis of strategic smart sustainable city development as part of futures studies. In a nutshell, it is to be applied in the academic context. The synthesis is based on the premise that while backcasting approaches or methodologies do differ in their steps and thus guiding questions, they do converge on the essentials. For example, most of the applied backcasting approaches include construction of the future vision and backcasting analysis. These must accordingly be included in the proposed scholarly and planning approach to strategic smart sustainable city development, with a slight difference brought to the guiding questions in accordance with the topic (see Table 4). In addition, the proposed approach is based on one normative vision. The backcasting approach is traditionally based on one normative vision, but multiple visions can also be used to explore different future alternatives [72]. Such a vision is prescriptive by focusing on what a smart sustainable city should be. As such, it aids researchers and scholars in clarifying shared values and preferences in terms of sustainability so they can develop visions of desirable

Table 3 Guiding questions for each step in the backcasting study

\begin{tabular}{|c|c|}
\hline Questions for backcasting steps & Methods and tools \\
\hline $\begin{array}{l}\text { Step 1: strategic problem orientation } \\
\text { What is the (socio-technical) system to be studied? } \\
\text { Which societal needs/functions are addressed by this system? } \\
\text { What are important trends and development related to this system/needs? } \\
\text { What are major sustainability problems and what are the causes? } \\
\text { How is the problem defined and what are possible problem perceptions? } \\
\text { Who are stakeholders and what are their opinions concerning sustainability } \\
\text { problems and possible solutions? }\end{array}$ & $\begin{array}{l}\text { Problem analysis; actor/stakeholder analysis; system analysis; } \\
\text { modeling methods; interactive methods }\end{array}$ \\
\hline $\begin{array}{l}\text { Step 2: generating sustainable future visions } \\
\text { What are the demands (terms of reference) for the future vision? } \\
\text { How does the future sustainable socio-technical system and need fulfillment look } \\
\text { like? } \\
\text { Which sustainability problems have been solved? } \\
\text { Which technologies have been used in the future vision? } \\
\text { How are culture and the social and economic structure different? } \\
\text { How do people live in the future vision? } \\
\text { How can it be made more sustainable and more attractive? }\end{array}$ & $\begin{array}{l}\text { Creativity methods; design methods; interactive methods; } \\
\text { modeling methods; visualization methods }\end{array}$ \\
\hline $\begin{array}{l}\text { Step 3: backcasting analysis } \\
\text { What technological changes are necessary for achieving the future vision? } \\
\text { What cultural and behavioral changes are necessary? } \\
\text { What structural, institutional, and regulatory changes are necessary? } \\
\text { How have necessary changes been realized and what stakeholder (groups) are } \\
\text { necessary? } \\
\text { Is it possible to define milestones for the identified technological, cultural, and } \\
\text { structural changes when looking back from the vision? }\end{array}$ & Backcasting analysis \\
\hline $\begin{array}{l}\text { Step 4: elaboration, design, analysis and defining follow-up agenda } \\
\text { What is a more detailed design of the socio-technical system in the future vision? } \\
\text { What are the results of different analyses (social, consumer, environmental, } \\
\text { economic, etc.)? } \\
\text { What are drivers, barriers, and conditions for the achieving the future vision? } \\
\text { What could different stakeholder groups (research, government, companies, public } \\
\text { interest) do and what should be on the action agenda? } \\
\text { Which activities can be started now and who should do them? } \\
\text { Elaborate a specific follow-up proposal that contributes to the system change and } \\
\text { define who should contribute and what should be contributed? }\end{array}$ & $\begin{array}{l}\text { Design methods; analytical methods such as impact assessment } \\
\text { and technology assessment; planning methods }\end{array}$ \\
\hline
\end{tabular}

Source: Quist et al. [56] 
Table 4 Steps and guiding questions of backcasting methodology and planning approach

Steps and guiding questions of backcasting methodology and planning approach

Step 1: defining normative assumptions and setting criteria and goals in relation to urban sustainability

What are the objectives with a description of the aim of the analysis in terms of its urban, environmental, socio-economic, and technological scope?

What specific sustainability and smartness goals are the objectives translated to for scenario analysis?

How should sustainability and smartness goals be integrated and complement each other in city development?

Step 2: describing the current situation, prevailing trends, and expected developments

What are the important global trends and developments related to city development?

What are the major urban sustainability problems and what are the causes and challenges?

Are the current situation, prevailing trends, and expected developments evaluated against the goals?

Which urban systems or domains are to be targeted?

Step 3: constructing an image of the future for smart sustainable city What are the demands (terms of reference) for the future vision?

How does the future smart sustainable city look like?

Which sustainability problems and challenges have been solved by achieving the goals?

Which technologies and their applications have been used in the future vision?

Step 4: backcasting analysis

What technological and urban changes are necessary for achieving the future vision?

What institutional, organizational, and regulatory changes are necessary?

How have necessary changes been realized and what stakeholders are necessary?

Step 5: elaboration and implementation

What are the results of environmental and socio-economic analyses in relation to urban sustainability?

How consistent are they with the specified goals and vision outcomes?

What political actions and institutional responses (city government, regulatory

body, industry, research community, etc.) are required for the implementation of

the vision and the policy measures implied in those actions and responses?

What should be on the action agenda?

(sustainable) futures. Indeed, it allows them to understand what they would prefer the future to be and then take the appropriate (or necessary) steps to create that preferred future. Furthermore, smart sustainable city development integrates and fuses sustainable development, technological development, and city development, forming an interdisciplinary and transdisciplinary area. Bibri [13] attempts to systematize the very complex and dense scientific area of smart sustainable cities in terms of identifying, distilling, and structuring the core dimensions of a foundational framework for smart sustainable city development as a set of future practices. The purpose is to set a framework that analytically relates city development, sustainable development, and ICT development while emphasizing how and to what extent sustainability and ICT have particularly become influential in city planning in the modern society. One implication of this is that a more appropriate backcasting methodology and planning approach to strategic smart sustainable city development should draw on insights (steps and guiding questions) from diverse methodologies or approaches in ways that embrace the three constituting strands of the development in question.
The key assumptions underlying this backcasting and planning approach include the following:

- Efficient utilization and conservation of land resources

- Decreasing energy usage through advanced ICT applications

- Integrating renewable and energy efficiency technologies/solutions

- Mitigating environmental impacts (GHG emissions and waste)

- Promoting sustainable transportation

- Safeguarding biodiversity and ecosystem

- Co-evolution of technology and city

- Goal-oriented

- Design-oriented

- Research-oriented

- Policy-oriented

- Time horizon of 25 years

\section{The outcome of the synthesis}

The intent of the above premises and assumptions is to provide the rationale for synthesizing the scholarly methodology and planning approach, which can be used to investigate and analyze the development of smart sustainable cities. Yet, the researchers and scholars' worldview and aim are the most important criteria that determine how futures studies on smart sustainable city development can be developed and conducted in terms of the details of the guiding questions. Futures studies dealing with the development of future models for the smart sustainable city can adopt backcasting as a scholarly methodology or planning approach to help identify and implement strategic decisions associated with urban sustainability. An example of a scholarly endeavor in this regard would be to investigate and analyze how to strategically assess, improve, and sustain the contribution of an integrated model of the most sustainably sound urban forms to the goals of sustainable development towards achieving sustainability-with support of ICT of pervasive computing in terms of its innovative solutions and sophisticated methods offered by smart city approaches-under what is labeled "smart sustainable cities" of the future (see [13] for a detailed overview). This research endeavor involves determining the most strategic steps to be taken to achieve smart sustainable cities as a vision of success or a desirable future.

However, the synthesis of the proposed scholarly and planning approach is based on the findings and insights drawn from the review and discussion of various backcasting approaches (namely $[2,22,33,35,36,51,56,57$, $61,63,76])$. It is further illustrated and supported by the case study presented and described in the next section. 


\section{Case study: the Project Gothenburg 2050 Overview of the Project Gothenburg 2050: aims, stakeholders, agreements, and outcomes}

As a research endeavor concerned with long-term sustainable images of the future to increase the potential of reaching a sustainable world, the Project Gothenburg 2050 aims to draw up and develop long-term visions for the sustainable city in Sweden that as part of a sustainable society could motivate a faster development towards sustainability. The project specifies energy and environment targets as part of a sustainable society with the principle of equity. The objective of the project is to develop, compile, and disseminate knowledge of what a sustainable society could look like and to stimulate research about long-term development. The intent of the project is to provide a basis for municipal and regional planning as well as strategic development. The research question addressed to the case involves actions that must be taken to achieve a long-term goal, that is, to attain a sustainability city, and what actions must be taken in relation to get there. After envisioning a successful outcome in this future scenario, then comes the question of what can be done in relation to energy, transport system, urban design, water and waste management, and food and grocery chain in order to achieve that outcome. This allows to ensure that strategies and actions are in the direction the stakeholders want to head. Next steps are usually based on reacting to present circumstances, creativity, intuition, and common sense but also (conceivably) are still aligned with the future vision and direction.

The project has initiated research, development, and demonstration endeavors involving a wide variety of stakeholders to discuss various aspects of the concept of a sustainable future and to participate in developing desirable future scenarios [51]. In this regard, it was carried out in cooperation between different stakeholders, including universities, energy companies, city government, public administration, and research councils. Specifically, the main stakeholders involved included the Chalmers University of Technology, Gothenburg University, Gothenburg Energi $\mathrm{AB}$, and the city of Gothenburg, in addition to the Swedish National Energy Administration (STEM), the Swedish Research Council for Environment, Agricultural Sciences and Spatial Planning (FORMAS), and Vastra Gotalandsregionen, and Renova. In relation to backcasting, in consultation exercises as part of the normative-oriented visionary model of backlisting, further insights were gained by comparing different normative scenarios arrived at or generated by these stakeholders towards a consensual outcome. In light of the backcasting endeavor, there was a general agreement between these stakeholders as to identifying the strategic steps or actions to pursue as well as to determine the feasibility of sustainable futures, with regard to the aforementioned urban domains and their integration. In fact, the Project Gothenburg 2050 was a participatory one in terms of the backcasting approach, with stakeholders in a real-life setting with their position and influence in the field, their interests, and their stakes being at play, as well as their relevant knowledge about the problems and possible solutions in terms of sustainability, in addition to the mutual support, learning, and commitment for implementation. In all, in strategically developing a sustainable city, the stakeholder group opted for using the best of what is new while retaining the best of what they already have, making use of what has worked well in the past in terms of urban sustainability planning and development as to the abovementioned urban domains.

The use of visions of a long-term future was an important tool for developing long-term strategies of a future city and surrounding regions. Like most backcasting approaches used in futures studies dealing with urban sustainability, backcasting is in this project concerned with the preferable (what we would prefer to happen in the future) and then explores strategies for achieving the sought goals with the knowledge of today about how the future could be. The backcasting process used in this project is based on the amalgamation of Robinson's [63] approach and the TNS framework [36].

As to the outcomes, in addition to being active in a number of planning processes, the project provides visionary and sustainability-focused input into the development of a new urban energy plan, sustainable transportation, urban planning, and water and waste management planning [51]. The project work within Gothenburg 2050 was completed in 2004. Important to note is that the actions for achieving a sustainable city in the future still continue in Gothenburg and the surrounding regions [51]. The images of the future for the sustainable city are expected to result in the implementation of different demonstrations and pilot projects, and knowledge and research results are being brought out to both societal actors and the public.

\section{City foresight methodology used in the Project Gothenburg 2050}

The methodology used in the Project Gothenburg 2050 (see Fig. 2) consists of four steps, namely [51]:

1. Description of the present and trend analysis

2. Setting criteria and goals (sustainability)

3. Developing images of the future

4. Analysis of how to reach the images

The first step aims to identify the problem and to describe the present situation. Existing trends addressed include energy systems, transportation, urban structure, eco-cycling, and food. The second step defines the 


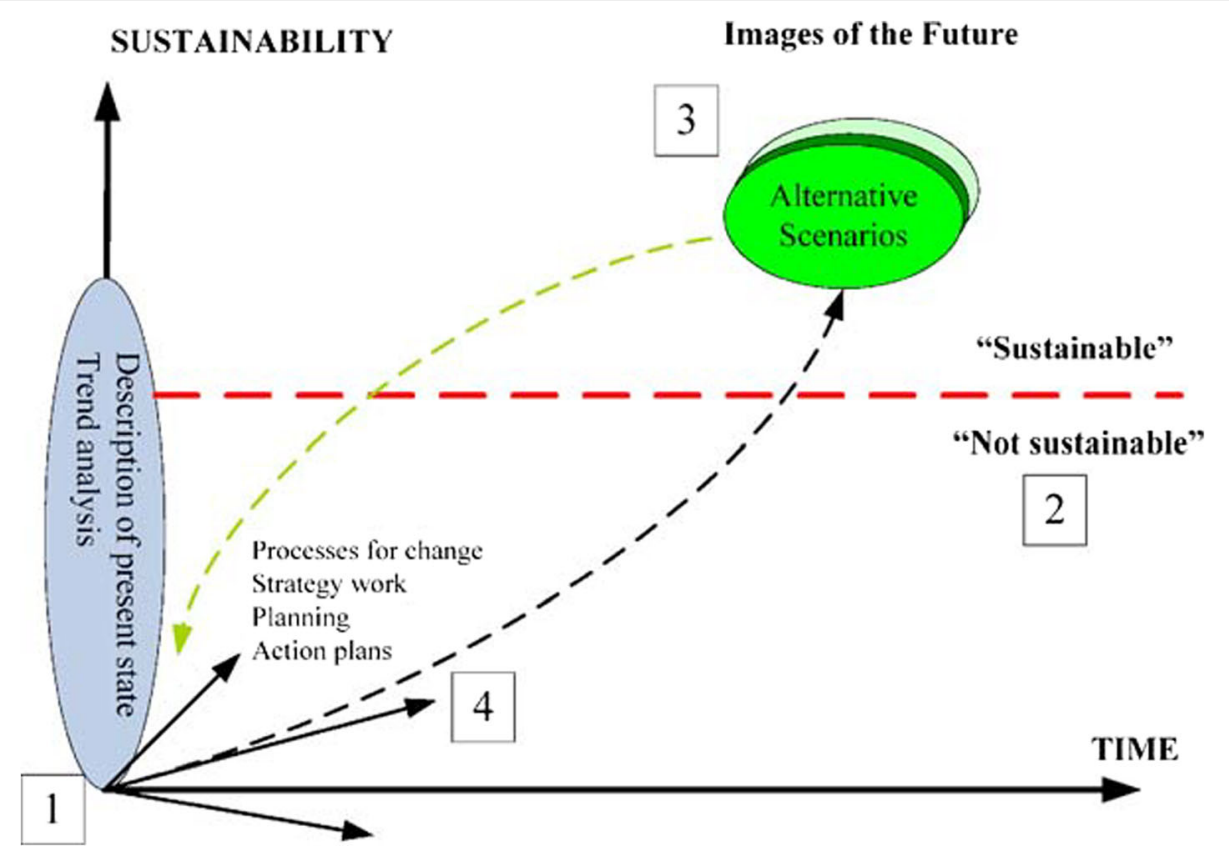

Fig. 2 The city foresight methodology use in the Project Gothenburg 2050. Source: Phdungsilp [51]. Illustrates the overall picture of the planning methodology used in the Project Gothenburg 2050, which consists of four steps, namely 1 description of the present and trend analysis, 2 setting criteria and goals (sustainability), 3 developing images of the future, and 4 analysis of how to reach the images

criteria, sets goals, and identifies limitations for the study, with consideration of a set of external factors that might affect the scenario. The third step constructs one or several alternative images of the future based on the criteria and goals chosen in the second step, indicating a solution to a major problem. The fourth step analyzes the possibilities to reach the society described in the alternative images.

The remaining part of this subsection presents different visions and scenarios in the Project Gothenburg 2050 pertaining to sustainable energy, transport system, urban design, water and waste management, and food and grocery chain. Worth noting is that sustainable city development is likely to involve different domains than these, as well as different aspects, depending on the social, cultural, economic, and political factors shaping the socio-technical landscape where the city is embedded as an amalgam of innovation systems. However, the visions and images were developed for strategic planning, following the definition of the criteria for sustainability and an analysis of the present state and trends in the relevant domains. Images of the future were developed based on a participatory approach, visualized using workshops and other inputs, compared to the present state and trends, and used for the planning process.

The sustainable energy system is a combination of smart and efficient use of energy, renewable energy supply (from biomass, wind, hydropower, solar electricity, etc.), changing lifestyle, energy-efficient urban planning, and energy storage in a hydrogen society. The energy supply was envisioned to be reduced by one-third; each person will use about 25,000 $\mathrm{kWh}$. The sustainable transport system is reliant on its closeness to daily activities to facilitate short-range trips and reduce travel needs, high accessibility, purpose-oriented and energy-efficient vehicles in pools, fewer and more fully loaded goods transportation, and fuel from the sun. This scenario shows that it is possible to decrease the energy use for transportation by almost $75 \%$ per capita due mainly to a reduction in short distant personal transportation. The sustainable urban design emphasizes compact city features: density, diversity, mixed land use, energy-efficient buildings, and closeness to transportation nodes and local squares, in addition to new rail systems and more space for bike and pedestrians as well as green areas. As to eco-cycling, it is concerned with waste management and sustainable water to significantly decrease the amount of waste through long-lasting products adapted to the ecosystem, re-use of products and material recycling, a clean and visible water environment, and few but safe final repositories. The scenario for a sustainable eco-cycle society shows that it is possible to half the total amount of waste compared with today, while unsorted mixed waste is envisioned to decrease by $70 \%$ compared to the total amount of waste today. The decrease in total amount of waste is a result of dematerialization, repair and re-use, durable product use, and lifestyle changes. The sustainable food and 
grocery chain focuses on working with sustainable and locally produced food, a diet with a higher proportion of vegetables, closeness between producers and consumers, food trade based in local squares, and conscious and energy-efficient consumption. The envisioned decrease concerns animal protein consumption as well as junk food and drinks.

\section{Backcasting as a useful tool for achieving urban sustainability: the shaping role of political action in sustainability transitions}

To move cities towards sustainability, policy actions should be fostered through relevant principles and values, and the environmental, social, and economic impacts associated with sustainability need to be anticipated and assessed. Being normative, backcasting is a suitable and useful framework for supporting policymakers and facilitating and guiding their actions to reach sustainability transitions. The choice of such framework to develop scenarios of smart sustainable cities is supported by its appropriateness to reach the policy targets (sustainable development goals) in tandem with societal and economic development. Also, scenarios based on backcasting may be capable of generating new policy directions needed if cities are to become smart sustainable (see [50] for guidelines towards environmentally sustainable transportation). The application of a backcasting approach assumes a vision of an evolutionary process of policy with a time frame of a generation (30 years), which is a basic principle to allow the policy actions to pursue the path towards smart sustainable cities as a sustainable transition. The backcasts of different alternative futures are intended to reveal the relative implications of different policy targets (see [62]), as well as to determine the opportunities for policymaking.

It is important to recognize the interplay between smart sustainable cities and other scales, as well as the links to political processes on a macro level, e.g., regulatory policies and governance arrangements [14]. To include, macro-processes of political regulation is central for the backcasting approach. One of the key actors involved in sustainability transition governance is government in terms of political mechanisms in the form of funding schemes, research management (regulation of public research institutes), innovation and technology policies, regulatory standards, market manipulations by the state, public-private collaborations and partnerships, and so on [11]. In this respect, government generates top-down pressure from regulation and policy and the use of market and other forms of incentives while promoting, spurring, and stimulating the collective learning mechanisms by supporting innovation financially and providing access to the needed knowledge [66].
The act of regulating entails a set of principles, rules, or laws designed to govern urban behavior in terms of development by carrying out legislations. Regulating city development through policies is the responsibility of many different government departments and agencies. In other words, regulations are issued and enforced by various regulatory bodies formed or mandated to carry out the provision or the intent of legislations. A city government affects urban development through regulatory policies, which aims to promote sustainability efforts. Most city governments have some regulations covering a variety of urban areas, including transport, traffic, mobility, environment, energy, land use, health, education, and safety in the context of sustainability.

In discursive terms, political action is of critical importance to the emergence, insertion, functioning, and evolution of smart sustainable cities as a new techno-urban discourse and an amalgam of innovation systems [14]. Indeed, political practice is at the core of the theory of discourse (e.g., [29]) and the theoretical framework of innovation system (e.g. [24, 41, 42, 58]) in terms of the shaping role of political mechanisms in the production and evolution of discourses and socio-technical systems governing technological innovations respectively. Recommendations for smart sustainable cities as a drastic techno-urban transformation, which entails a set of intertwined socio-technical systems and a cluster of interrelated discourses embedded in the wider socio-technical landscape, are unlikely to proceed without parallel political actions. Drastic shifts to sustainable technological regimes "entail concomitantly radical changes to the socio-technical landscape of politics, institutions, the economy, and social values" ([69], p. 131). From a discursive perspective, political processes are at the heart of material mechanisms and practices in terms of translating the vision of smart sustainable cities into concrete projects and strategies and their institutionalization in urban structures and practices [14]. And from an innovation system perspective, political processes represent the set-up under which dynamic networks of urban actors and entities can interact within diverse industrial sectors in the development, diffusion, and utilization of knowledge and technology pertaining to sustainable urban development.

Smart sustainable cities as an urban transformation have a quite strong governmental and policy support, particularly within ecologically and technologically advanced societies [14]. The underlying idea figures in many policy documents and agenda as well as political statements and argumentations, in addition to being used by many organizations and institutions (e.g., industries, universities, research institutes, etc.), it is not an element closed in the "ivory tower" of the research community, but it is influenced by the macro-political 
practices in connection with sustainable development and ICT innovation [14]. This is anchored in the premise that drastic urban shifts are unlikely to proceed without parallel political action to reiterate. As a corollary of its dynamic interaction with new discourses, politics forces their emergence, functioning, and evolution [29].

However, the number of methods and tools to develop sustainability and operationalize sustainable development has, over the past two decades, grown rapidly. The complexity of planning for sustainability has emphasized the importance of applying the backcasting approach to have an informed vision of specific goals so as to strategically deal with potential trade-off among different decisions and actions, as current trends, actions, and plans are usually part of the problem [61]. The prominence of backcasting as a form of strategic thinking and problem-solving framework lies in that it focuses on the long-term consequences and problems of the present decisions and actions based on the discussion of various alternatives from a sustainability perspective. Sustainability takes into account that current trends should only influence the initial scale of the transition (e.g., smart sustainable cities), not its direction, which is the epitome of backcasting. Grounded in holistic thinking, sustainability is based on the idea of consciously and incessantly going with the grain of nature and providing the conditions for deploying the frameworks necessary for its operationalization and its translation into practices in a more dynamically innovative way in order to reach a sustainable society [12]. As such, it is based on an all-embracing understanding of the complex challenges and mounting problems facing the society, which is necessary for making all-inclusive decisions and taking well-informed actions for its long-term benefit, thereby the relevance of applying the backcasting approach. Yet, the backcasting approach should be complemented by the more commonly applied forecasting approach. If forecasting is the sole planning strategy, there are substantial risks that "fixing the problem" will retain the principle mechanisms from which that problem originates in the first place [47]. In other words, forecasting is unlikely to generate solutions that presuppose the breaking of trends, which may pose an issue for planning in the long run due to the discontinuities that are most likely to emerge or occur. In relation to this argument, Dreborg [27] underscores that the way we perceive the possible or reasonable may be a major obstacle to a real change.

To achieve sustainability goals requires an amalgamation of technological, social, cultural, political, institutional, and organizational changes that are to affect and shape the actions of many stakeholders when they are diffused into or permeate society. Such changes involve a complex process of transformation on the long term, especially in the context of smart sustainable cities which are very complex due to the inherent uncertainty of the future, the inherent dynamically changing nature of the urban environment, and the inherent ambiguity of stakeholders having different and sometimes conflicting value sets. Planning for urban sustainability requires novel methods and paradigms as alternative approaches to traditional planning (see $[67,68])$. This is predicated on the assumption that it is necessary to understand the possible linkages among environmental, socio-economic, and institutional processes. Similarly, any resultant solution from backcasting would broadly affect many stakeholders across a multitude of societal dimensions, such as technological, social, cultural, institutional, political, and organizational.

\section{Conclusions}

The principle aim of this paper was to review the existing backcasting methodologies and discuss the relevance of their use in terms of their steps and guiding questions in analyzing strategic smart sustainable city development as an area that is at the intersection of city development, sustainable development, and technology development, as well as to synthesize a backcasting approach based on the outcome of the review and discussion, which in turn is illustrated by the Gothenburg 2050 Project as a case study. Smart sustainable cities are seen as the most important arena for sustainability transitions and thus of crucial importance for global futures, as they constitute key sites of environmental, economic, and social innovations making significant contributions to societal transformation and cultural advancement. However, there is no single or simple formula for achieving smart sustainable cities. Drastic changes of such kind require long-term strategic planning, where futures studies can serve as a basis for inspiration in discussion and decision-making processes. The primary purpose of futures studies is to get a better understanding of future opportunities and to explore the implications of alternative development paths that can be relied on either to adapt or to avoid the impacts of the future. There is a belief that future-orientated planning can change development paths. The interest in smart sustainable city future is driven by a willingness and desire to transform the continued development path. Further, there are a number of different approaches to futures studies. Of these, backcasting is the most promising approach to developing action plans for achieving urban sustainability, more specifically smart sustainable cities. Using backcasting, futures studies are intended in this context to help people better understand future possibilities of models for smart sustainable city and their feasibility and potential in order to make better decisions today. They are also intended to challenge present systems or to influence the future or adapt to the most likely future. Creating a choice of the future by outlining sustainable 
alternative forms the basis for strategic planning. Also, they are meant to aid people in examining and clarifying their normative scenarios of the future, transforming their visions, and then developing action plans. In view of that, they can be used to provide an analytical framework for policy decisions in the identification of opportunities for integrating the novel applications of advanced ICT with the design concepts and planning principles of sustainable urban forms in the context of smart sustainable cities of the future [12, 13]. The role of futures studies has become of central importance for policy-making process in the context of urban sustainability. Being normative, futures studies provide a useful framework for supporting policymakers and facilitating and guiding their actions to reach urban sustainability. Also, alternative futures based on backcasting are capable of generating new policy directions needed if cities are to become smartly sustainable, reveal the relative implications of policy targets, and determine new opportunities for policymaking. Furthermore, backcasting encourages the searching for new development paths when the conventional ones do not seem to solve the problem, or when the available solutions may create new problems. Accordingly, it is clear that backcasting as a scholarly and planning approach dominates in dealing with strategic planning and development in the context of urban sustainability, not least within technologically and ecologically advanced nations in Europe. The backcasting has been applied to different urban domains in the context of urban sustainability, including energy, mobility, transportation, land use, environment, waste management, and design. Thus, backcasting has been employed on a variety of topics related to different aspects of urban sustainability. Urban policymakers should be encouraged to understand the past, present, and future conditions of their cities to determine the most strategic steps to achieve different forms of success pertaining to the long-term goals of sustainability in an increasingly technologized and computerized urban world. In this respect, the focus of backcasting studies is on the key unexploited benefits, opportunities, capabilities, impacts, possible routes, and future scenarios enabled by ICT of pervasive computing for urban sustainability in terms of advancing sustainable urban forms in such a way to strategically assess, improve, and sustain their contribution to the goals of sustainable development $[12,13]$.

In general, the backcasting approach is found to be well-suited for long-term urban sustainability solutions and indeed is the most widely recognized and applied approach to futures studies dealing with urban sustainability issues due to its normative, goal-oriented, and problem-solving character. Also, it is useful when dealing with complex problems and transitions, the current trends are part of the problem, and different directions of development can be allowed given the wide scope and long time horizon considered. A number of recent futures studies using backcasting have underlined the efficacy of this scholarly and planning approach in terms of indicating policy pathway for sustainability transitions and thus supporting policymakers and facilitating and guiding their actions. The synthesized scholarly and planning approach serves to help researchers and scholars in analyzing strategic smart sustainable city development to assist planners, policymakers, and decision-makers in their endeavor to implement smart sustainable cities. In addition, it is meant to save the time and effort involved in reviewing, contextualizing, and adapting available methodological frameworks for backcasting to develop future models for smart sustainable city, a holistic urban development approach that will prevail for many years that yet to come due to the global trends currently at play across the world: the diffusion of sustainability, the spread of urbanization, and the rise of ICT.

Most of the above concluding claims ought to be treated relative to several factors in terms of the effectiveness of any proposed backcasting approach as to the actions identified and the policy measures determined to attain desirables futures, despite the appropriateness of this approach to developing long-term strategies and reaching policy targets (e.g., urban sustainable development goals) as well as generating new policy directions (see [50]). In particular, there is an interplay between societal goals (e.g., smart sustainable cities) and other scales, in addition to the links to political processes on a macro-level, e.g., regulatory policies and governance arrangements. To include, macro-processes of political regulation is central for the backcasting approach. One of the key actors involved in sustainability transition governance is government in terms of political mechanisms in the form of funding schemes, research management (regulation of public research institutes), innovation and technology policies, regulatory standards, market manipulations by the state, public-private collaborations and partnerships, and so on [11]. In this respect, the government generates top-down pressure from regulation and policy and the use of market and other forms of incentives, while promoting, spurring, and stimulating the collective learning mechanisms by supporting innovation financially and providing access to the needed knowledge [66]. These actions are of a central role in implementing the strategies developed by the stakeholders involved in the backcasting endeavors. Besides, drastic shifts to sustainable systems "entail concomitantly radical changes to the socio-technical landscape of politics, institutions, the economy, and social values" ([69], p. 131). Regardless, the complexity of planning for urban sustainability has emphasized the importance of applying the backcasting approach to have an informed vision of specific goals so as to strategically deal with potential trade-off among different decisions and 
actions, as current trends, actions, and plans are usually part of the problem.

Furthermore, there are several approaches to backcasting. While they differ in their steps and thus guiding question, they do converge on the essentials. The backcasting framework is adaptive in nature within its steps and thus guiding questions based on the specific context under which it is applied, the stakeholders involved, and the complementary methods to be used. Therefore, it is common to adjust the backcasting framework for application in different research projects depending on the topic, purpose, scope, and complexity of futures studies to undertake, as well as on the time and resources available and the presence of dependencies between stakeholders and power issues among them. For example, taking into account all the dimensions of participatory backcasting in an integral approach in a rather limited timeframe might result in some tension between, on the one hand, the adherence to the application of all the steps of the backcasting approach by soundly using the related guiding questions and, on the other hand, obtaining the results on the topic that make sufficient sense and derive from a deeper understanding of the approach and its range of dimensions (see [56]). Interestingly, different approaches are emerging in the field of urban sustainability within various city domains.

In light of the above, this paper endeavored to synthesize a scholarly and planning approach based on the findings and insights drawn from the review and discussion of various backcasting approaches and further illustrated it by the case study the Gothenburg 2050 Project. Below is the outline of the synthesized scholarly and planning approach to strategic smart sustainable city development:

- Defining normative assumptions and setting criteria and goals in relation to urban sustainability

- Describing the current situation, prevailing trends, and expected developments

- Constructing an image of the future for smart sustainable city

- Backcasting analysis

- Elaboration and implementation

The work of the Project Gothenburg 2050 is a Swedish exemplar case in the application of backcasting for strategic sustainable urban planning. It uses backcasting to develop action plans from a shared vision of the future sustainable city. This vision is a result of the concept of sustainability as clarified by the involved stakeholders. It is a research project in its nature. It tries to develop, compile, and disseminate knowledge of sustainable society. Hence, it seems theoretical in its overall approach. In it, the driving factor is to achieve the sustainable society that is defined by the project's stakeholders. The project engages with universities, research councils, the energy sector, local government, and citizens who are interested in the project.

\section{Abbreviations}

ICT: Information and Communication Technology; STD: Sustainable Technology Development; TNS: The Natural Step

\section{Funding}

The study is an integral part of a Ph.D. research project being carried out at NTNU.

\section{Author's contributions}

The author read and approved the final manuscript.

\section{Author's information}

Simon Elias Bibri is a Ph.D. scholar in the area of smart sustainable cities of the future and assistant professor at the Norwegian University of Science and Technology (NTNU), Department of Computer and Information Science and Department of Urban Design and Planning, Trondheim, Norway. His intellectual pursuits and endeavors have hitherto resulted in an educational background encompassing knowledge from, and meta-knowledge about, different academic and scientific disciplines. He holds a Bachelor of Science in Computer Engineering and ten Masters of Science in diverse areas. Bibri has earned all his master's degrees from different universities in Sweden, namely Lund University, West University, Blekinge Institute of Technology, Malmö University, Stockholm University, and Mid Sweden University. He served as a sustainability and ICT strategist, business engineer, researcher, and consultant.

Bibri's current research interests include the following areas: ICT visions of pervasive computing, big data analytics and context-aware computing, sustainable urban planning and development, sustainable cities, smart cities, sustainability transitions, and technological innovation systems. He is the author of two academic books in the field of pervasive computing and one (recently published) book in the field of smart sustainable urban planning and development

\section{Competing interests}

The author declares that he has no competing interests.

\section{Publisher's Note}

Springer Nature remains neutral with regard to jurisdictional claims in published maps and institutional affiliations.

Received: 9 January 2018 Accepted: 21 June 2018

Published online: 27 July 2018

\section{References}

1. Ahvenniemi H, Huovila A, Pinto-Seppä I, Airaksinen M (2017) What are the differences between sustainable and smart cities? Cities 60:234-245

2. Akerman J, Höjer M (2006) How much transport can the climate stand?-Sweden on a sustainable path in 2050. Energy Policy 34(14):1944-1957

3. Al Nuaimi E, Al Neyadi H, Nader M, Al-Jaroodi J (2015) Applications of big data to smart cities. J Internet Serv Appl 6(25):1-15

4. Angelidou M, Psaltoglou A (2017) An empirical investigation of social innovation initiatives for sustainable urban development. Sustain Cities Soc 33:113-125

5. Angelidou M, Psaltoglou A, Komninos N, Kakderi C, Tsarchopoulos P, Panori A (2017) Enhancing sustainable urban development through smart city applications. J Sci Technol Policy Manage:1-25

6. Banister D (2006) City future transport. Keynote paper for transport planning - a design challenge? In: Conference organised by AMIDST at the University of Amsterdam, Amsterdam, 14-16 June 2006

7. Banister D, Stead D (2004) The impact of ICT on transport. Transp Rev 24(5): 611-632

8. Banister D, Stead D, Steen P, Dreborg KH, Akerman J, Nijkamp P et al (2000) European transport policy and sustainable mobility. Spon Press, London 
9. Batty M, Axhausen KW, Giannotti F, Pozdnoukhov A, Bazzani A, Wachowicz M, Ouzounis G, Portugali Y (2012) Smart cities of the future. Eur Phys J 214 $481-518$

10. Bettencourt LMA (2014) The uses of big data in cities. Santa Fe Institute, Santa Fe, New Mexico

11. Bibri SE (2015b) The shaping of ambient intelligence and the internet of things: historico-epistemic, socio-cultural, politico-institutional and ecoenvironmental dimensions. Springer, Berlin

12. Bibri SE (2018a) Smart sustainable cities of the future: the untapped potential of big data analytics and context aware computing for advancing sustainability. Springer, Berlin

13. Bibri SE (2018b) A foundational framework for smart sustainable city development: theoretical, disciplinary, and discursive dimensions and their synergies. Sustain Cities Soc 38:758-794

14. Bibri SE, Krogstie J (2016) On the social shaping dimensions of smart sustainable cities: a study in science, technology, and society. Sustain Cities Soc 29:219-246

15. Bibri SE, Krogstie J (2017a) Smart sustainable cities of the future: an extensive interdisciplinary literature review. Sustain Cities Soc 31:183-212

16. Bibri SE, Krogstie J (2017b) ICT of the new wave of computing for sustainable urban forms: their big data and context-aware augmented typologies and design concepts. Sustain Cities Soc 32:449-474

17. Bicchieri C (2005) The grammar of society: the nature and dynamics of social norms. Cambridge University Press, Cambridge

18. Bicchieri C (2017) Norms in the wild: how to diagnose, measure, and change social norms. Oxford University Press, Oxford

19. Bifulco F, Tregua M, Amitrano CC, D'Auria A (2016) ICT and sustainability in smart cities management. Int J Public Sect Manage 29(2):132-147

20. Borjeson $L$ et al (2006) Scenario types and techniques: towards a user's guide. Futures 38(2006):723-739

21. Campbell S (1996) Green cities, growing cities, just cities? Urban planning and the contradictions of sustainable development. J Am Plan Assoc 62(3):296-312

22. Carlsson-Kanyama A, Dreborg KH, Eenkhorn BR, Engström R, Falkena B (2003) Image of everyday life in the future sustainable city: experiences of back-casting with stakeholders in five European cities. The Environmental Strategies Research Group (Fms) - report 182, the Royal Institute of Technology, Stockholm, Sweden, 2003. Report available at/react-text www infrakthsereact-text:563

23. Carlsson-Kanyama A, Dreborga KH, Mollb HC, Padovan D (2008) Participative backcasting: a tool for involving stakeholders in local sustainability planning. Futures 40(1):34-46

24. Chaminade C, Edquist C (2010) Inside the public scientific system: changing modes of knowledge production. In: Smits R, Shapira P, Kehlmann S (eds) The theory and practice of innovation policy: an international research handbook. Edward Elgar, Cheltenham, pp 95-114

25. Chatterjee K, Gordon A (2006) Planning for an unpredictable future: transport in Great Britain in 2030. Transp Policy 13(2006):254-264

26. Creutzig F, Baiocchi G, Bierkandt R, Pichler PP, Seto KC (2015) A global typology of urba energy use and potentials for an urbanization mitigation wedge. Proc Natl Acad Sci USA 112:6283-6288.

27. Dreborg KH (1996) Essence of backcasting. Futures 28(9):813-828

28. European Commission (2011) Cities of tomorrow. Challenges, visions, ways forward. Publications Office of the European Union, Brussels

29. Foucault M (1972) The archaeology of knowledge. Routledge, London

30. Green K, Vergragt P (2002) Towards sustainable households: a methodology for developing sustainable technological and social innovations. Futures 34:381-400

31. Hofstad H (2012) Compact city development: high ideals and emerging practices. Eur J Spat Plan, pp 1-23.

32. Höjer M (2000) What is the point of IT? Backcasting urban transport and land-use futures. Doctoral dissertation, Department of Infrastructure and Planning. The Royal Institute of Technology, Stockholm

33. Höjer M, Mattsson L-G (2000) Historical determinism and backcasting in futures studies. Futures 2000:613-634

34. Höjer M, Wangel S (2015) Smart sustainable cities: definition and challenges. In: Hilty L, Aebischer B (eds) ICT innovations for sustainability. Springer, Berlin, pp 333-349

35. Holmberg J (1998) Backcasting: a natural step in operationalizing sustainable development. Greener Manage Int (GMI) 23:30-51

36. Holmberg J, Robèrt KH (2000) Backcasting from non-overlapping sustainability principles: a framework for strategic planning. Int I Sustain Dev World Ecol 74:291-308
37. Jabareen YR (2006) Sustainable urban forms: their typologies, models, and concepts. J Plann Educ Res 26:38-52

38. Jacobs J (1961) The death and life of great American cities. Random House, New York

39. Jansen JLA (1994) Towards a sustainable future, en route with technology In: The dutch committee for long-term environmental policy (ed) the environment: towards a sustainable future. Kluwer, Dordrecht, pp 497-523

40. Kärrholm M (2011) The scaling of sustainable urban form: some scale-related problems in the context of a Swedish urban landscape. Eur Plan Stud 19(1):97-112.

41. Kemp R (1997) Environmental policy and technical change: a comparison of the technological impact of policy instruments. Edward Elgar, Cheltenham

42. Kemp R, Rotmans J (2005) The management of the co-evolution of technical, environmental and social systems. In: Weber M, Hemmelskamp J (eds) Towards environmental innovation systems. Springer, Berlin

43. Kramers A, Höjer M, Lövehagen N, Wangel J (2014) Smart sustainable cities: exploring ICT solutions for reduced energy use in cities. Environ Model Softw 56:52-62

44. Ling T (2002) Contested health futures. In: Brown N, Rappet B, Webster A (eds) Contested futures: a sociology of prospective techno-science. Ashgate, Aldershot

45. Lynch K (1981) A theory of good city form. MIT Press, Cambridge

46. McHarg IL (1995) Design with nature. Wiley, London

47. Miola A (2008) Backcasting approach for sustainable mobility. European Commission, Joint Research Centre, Institute for Environment and Sustainability

48. Mumford L (1961) The city in history: its origins, its transformations, and its prospects. Harcourt Brace and World, New York

49. Nigel T (2007) Urban planning theory since 1945. Sage, London

50. OECD (2002) OECD guidelines towards environmentally sustainable transport. OECD, Paris

51. Phdungsilp A (2011) Futures studies' backcasting method used for strategic sustainable city planning. Futures 43(7):707-714

52. Quist J (2002) A strategic approach to radical sustainable innovations: stakeholder involvement, visioning, backcasting, learning and engineering education. In: Mulder KF (ed) Proceedings of the first engineering education in sustainable development (EESD) conference. Delft, pp 626-637

53. Quist J (2007) Backcasting for a sustainable future: the impact after 10 years. Ph.D. thesis, Faculty of Technology, policy and management, Delft University of Technology, Delft

54. Quist J (2009) Stakeholder and user involvement in backcasting and how this influences follow-up and spin-off. Faculty of Technology, Policy and Management, Delft University of Technology

55. Quist J, Knot M, Young W, Green K, Vergragt P (2001) Strategies towards sustainable households using stakeholder workshops and scenarios. Int J Sustain Dev 4:75-89

56. Quist J, Rammelt C, Overschie M, de Werk G (2006) Backcasting for sustainability in engineering education: the case of Delft University of Technology. J Clean Prod 14:868-876

57. Quist J, Vergragt PJ (2006) Past and future of backcasting: the shift to stakeholder participation and proposal for a methodological framework. Futures 38(2006):1027-1045

58. Rånge M, Sandberg M (2015) Windfall gains or eco-innovation? "Green" evolution in the Swedish innovation system. Soc Environ Econ Policy Stud:1-20

59. Richardson N (1989) Land use and planning and sustainable development in Canada. Canadian Environmental Advisory Council, Ottawa

60. Robèrt KH (2000) Tools and concepts for sustainable development, how to they relate to a general framework for sustainable development, and to each other? J Clean Prod 8(2000):243-254

61. Robert KH, Schmidt-Bleek B, Larderel JA, Basile G, Jansen JL, Kuehr R (2002) Strategic sustainable development-selection, design and synergies of applied tools. J Clean Prod 10:197-214

62. Robinson J (1982) Energy backcasting - a proposed method of policy analysis. Energy Policy 12(1982):337-344

63. Robinson J (1990) Futures under glass: a recipe for people who hate to predict. Futures 22(8):820-842

64. Robinson J (2003) Future subjunctive: backcasting as social learning. Futures 35:839-856

65. Roth A, Kaberger T (2002) Making transport sustainable. J Clean Prod 10: 361-371

66. Rotmans J, Kemp R, van Asselt M (2001) More evolution than revolution: transition management in public policy. Foresight 3(1) 
67. Rotmans J, van Asselt M, Vellinga P (2000b) Assessment methodologies for urban infrastructure: an integrated planning tool for sustainable cities. Environ Impact Assess Rev 20:265-276

68. Rotmans J et al (2000a) Visions for a sustainable Europe. Futures 32(2000): 809-831

69. Smith A (2003) Transforming technological regimes for sustainable development: a role for alternative technology niches? Sci Public Policy 30(2):127-135

70. Taghavi M, Bakhtiyari K, Taghavi H, Olyaee Attar V, Hussain A (2014) Planning for sustainable development in the emerging information societies. J Sci Technol Policy Manage 5(3):178-211

71. Tinker J (1996) From 'introduction' ix-XV. In: Robinson JB et al (eds) Life in 2030: exploring a sustainable future for Canada. University of British Columbia Press, Vancouver

72. Tuominent A, Tapio P, Banister D, Jarvi T (2014) Pluralistic backcasting: integrating multiple visions with policy packages for transport climate policy. Futures 60:41-58

73. United Nations (2015a) Big Data and the 2030 agenda for sustainable development. Prepared by A. Maaroof. Available at: https://www.unescap. org/sites/default/files/2_Meeting\%20Report_ Big\%20Data\%20and\%20the\%202030\%20Agenda_2016.pdf. Accessed 7 Jan 2018.

74. United Nations (2015b) Habitat III Issue Papers, 21-Smart cities (V2.0), New York, NY. Available at: https://collaboration.worldbank.org/docs/DOC-20778. Accessed 2 May 2017

75. United Nations (2015c) Transforming our world: the 2030 agenda for sustainable development, New York, NY. Available at: https:// sustainabledevelopment.un.org/post2015/transformingourworld

76. Weaver P, Jansen L, van Grootveld G, van Spiegel E, Vergragt P (2000) Sustainable technology development. Greenleaf Publishers, Sheffield

77. Wheeler SM, Beatley T (eds) (2010) The sustainable urban development reader. Routledge, London, New York

78. Williams K (2009) Sustainable cities: research and practice challenges. Int J Urban Sustain Dev 1 (1):128-132.

\section{Submit your manuscript to a SpringerOpen ${ }^{\circ}$ journal and benefit from:}

- Convenient online submission

- Rigorous peer review

- Open access: articles freely available online

- High visibility within the field

- Retaining the copyright to your article

Submit your next manuscript at $\boldsymbol{\nabla}$ springeropen.com 